\title{
The relationship of body fatness to female attractiveness
}

Guanlin Wang, Kurosh Djafarian, Chima A. Egedigwe, Asmaa El hamdouchi, Robert Ojiambo, Harris Ramuth, Sandra Johanna Wallner-Liebmann, Sonja Lackner, Adama AD Diouf, Justina Sauciuvenaite, Catherine Hambly, Lobke M. Vaanholt, Mark D. Faries, John R Speakman

Aspects of the female body may be attractive because they signal evolutionary fitness. Greater body fatness might reflect greater potential to survive famines, but individuals carrying larger fat stores may have poor health and lower fertility in non-famine conditions. A mathematical statistical model using epidemiological data linking fatness to fitness traits, predicted a peaked relationship between fatness and attractiveness (maximum at body mass index (BMI) $=23.2$ to 24.8 depending on ethnicity and assumptions). Participants from three Caucasian populations (Austria, Lithuania and the UK), three Asian populations (China, Iran and Mauritius) and four African populations (Kenya, Morocco, Nigeria and Senegal) rated attractiveness of a series of female images varying in fatness (BMI) and waist to hip ratio (WHR). There was an inverse linear relationship between physical attractiveness and body fatness or BMI in all populations. Lower body fat was more attractive, down to at least BMI $=19$. There was no peak in the relationship over the range we studied in any population. WHR was a significant independent but less important factor, which was more important (greater $r^{2}$ ) in African populations. Predictions based on the fitness model were not supported. Raters appeared to use body fat percentage (BF \%) and BMI as markers of age. The covariance of $\mathrm{BF} \%$ and $\mathrm{BMI}$ with age indicates that the role of body fatness alone, as a marker of attractiveness, has been overestimated. 
2 Guanlin Wang ${ }^{1}$, Kurosh Djafarian², Chima A. Egedigwe ${ }^{3}$, Asmaa El Hamdouchi ${ }^{4}$, Robert

3 Ojiambo $^{5}$, Harris Ramuth ${ }^{6}$, Sandra Johanna Wallner-Liebmann ${ }^{7}$, Sonja Lackner ${ }^{7}$, Adama AD

4 Diouf $^{8}$, Justina Sauciuvenaite ${ }^{9}$, Catherine Hambly ${ }^{9}$, Lobke M. Vaanholt ${ }^{9}$, Mark D. Faries ${ }^{10}$ and

5 John. R Speakman ${ }^{1,9}$

7 1. State Key Laboratory of Molecular Developmental Biology, Institute of Genetics and

8 Developmental Biology, Chinese Academy of Sciences, Beijing, China

9 2. Department of Clinical Nutrition, Tehran University of Medical Sciences, Tehran, Iran

10 3. Department of Biochemistry, Michael Okpara University of Agriculture, Umuahia, Abia

11 State, Nigeria

12 4. CNESTEN, Unité Mixte de Recherche Nutrition et Alimentation, CNESTEN-Université Ibn

13 Tofail, Rabat, Morocco

14 5. College of Health science, School of Medicine, Medical physiology department,, Moi

15 University, Eldoret, Kenya

16 6. Biochemistry department, Central health Laboratory services, Ministry of health and

17 Quality of life, Mauritius

18 7. Center of Molecular Medicine, Institute of Pathophysiology and Immunology, Medical

19 University Graz, Graz, Austria

20 8. Laboratoire de Nutrition, Département de Biologie Animale, Faculté des Sciences et

21 Techniques, Université Cheikh Anta Diop de Dakar, Dakar, Senegal 
9. Institute of Biological and Environmental Sciences, University of Aberdeen, Aberdeen, UK;

10. Stephen F. Austin State University, Nacogdoches Texas, USA

\section{Corresponding Author:}

Dr John R. Speakman

State Key laboratory of Molecular Developmental Biology, Institute of Genetics and

Developmental Biology, Chinese Academy of Sciences, Beijing, 100101, China.

Phone number: +8615810868669

Email: j.speakman@,abdn.ac.uk

Key words: mate selection, evolution, female physical attractiveness, body fat, waist to hip ratio, 
44 Abstract:

45

46

47

\section{1}

Aspects of the female body may be attractive because they signal evolutionary fitness. Greater body fatness might reflect greater potential to survive famines, but individuals carrying larger fat stores may have poor health and lower fertility in non-famine conditions. A mathematical statistical model using epidemiological data linking fatness to fitness traits, predicted a peaked relationship between fatness and attractiveness (maximum at body mass index $(\mathrm{BMI})=23.2$ to 24.8 depending on ethnicity and assumptions). Participants from three Caucasian populations (Austria, Lithuania and the UK), three Asian populations (China, Iran and Mauritius) and four African populations (Kenya, Morocco, Nigeria and Senegal) rated attractiveness of a series of female images varying in fatness (BMI) and waist to hip ratio (WHR). There was an inverse linear relationship between physical attractiveness and body fatness or BMI in all populations. Lower body fat was more attractive, down to at least BMI $=19$. There was no peak in the relationship over the range we studied in any population. WHR was a significant independent but less important factor, which was more important (greater $\left.\mathrm{r}^{2}\right)$ in African populations. Predictions based on the fitness model were not supported. Raters appeared to use body fat percentage (BF $\%$ and $\mathrm{BMI}$ as markers of age. The covariance of $\mathrm{BF} \%$ and $\mathrm{BMI}$ with age indicates that the role of body fatness alone, as a marker of attractiveness, has been overestimated. 
Introduction

Mate selection is a key behavioral component of reproduction related to the survival of ones' genes in the future gene pool (Andersson \& Simmons 2006; Trivers 1985). Our perceptions of attractiveness of potential mates is complex and multi-dimensional, and may include many diverse aspects. These include economic parameters, like possessions, wealth and social economic status (SES) (Drury 2000; Swami et al. 2010), psychological components such as cognitive ability, behavior, personality and social competence (Eagly et al. 1991), physiological aspects such as the major histocompatibility complex status (Thornhill et al. 2003), hormone levels (Pawlowski \& Sorokowski 2008) and age (Borgerhoff Mulder 1998). In addition, physical aspects such as leg length (Swami et al. 2006b), the shape of the face (Grammer \& Thornhill 1994; Perrett et al. 1998) and shape of the body (Fallon \& Rozin 1985; Furnham et al. 1997; Singh 1993; Singh \& Young 1995; Swami et al. 2006a; Swami \& Tovee 2005; Tovée et al. 2006; Tovee \& Cornelissen 2001; Tovee et al. 2002; Wass et al. 1997) including the role of symmetry (Perrett et al. 1998; Singh 1993; Singh \& Young 1995; Smith et al. 2007; Tovee \& Cornelissen 2001; Tovee et al. 2002) are also significant factors affecting attractiveness. The relative importance of these different dimensions for physical attractiveness may vary between the sexes and across cultures.

One aspect of attractiveness that has received considerable previous attention is the factors that drive perceptions of attractiveness of the female body (non-facial). Early studies focused on waist to hip ratio (WHR) (Singh 1993; Tovee et al. 2002). A suggested preference for an optimal 
WHR around 0.7 has been generally interpreted within an evolutionary context because higher values of WHR are related to elevated risks of cardiovascular disease (Terry et al. 1992), diabetes (Chan et al. 1994) and cancer (Borugian et al. 2003). However, Lassek and Gaulin (2008) have suggested that WHR is not associated with health but more related to cognitive abilities. It has been noted, however, that WHR is not independent of body fatness, which may itself be an indicator of physical attractiveness. More recent work therefore has attempted to partition the importance of these two factors, and it has been conclusively shown across numerous studies that variation in attractiveness is much more closely related to variation in body fatness than to differences in WHR (e.g. Henss 2000; Kościński 2013; Smith et al. 2007; Tassinary \& Hansen 1998; Tovee \& Cornelissen 1999; Tovee et al. 2002; Tovee et al. 1999; Tovee et al. 1997; Tovee et al. 1998).

Although many previous studies have set their observations into a post hoc evolutionary rationalization (e.g. Borugian et al.2003), few studies have attempted to predict a priori the impact of different levels of body fatness based on an evolutionary model. Recent large scale epidemiological studies, linking variation in body fatness with risks of disease and fertility, and mathematical models that enable modeling of the relationship between fatness and famine survival, provide an opportunity to model much more closely the expected shape of the relationship between fatness and evolutionary fitness, and hence test whether physical attractiveness is indeed a marker of fitness. We argue that if physical attractiveness is related to fitness, then the relationship between body fatness and physical attractiveness should mirror the relationship between fatness and fitness. Our aim was to develop such a model for the role of 
body fatness in physical attractiveness using where available culture specific data and then test

the model across a range of different cultures, using a common protocol. We sampled

108

109

110

111

112

113

114

115

116

117

118

119

120

121

122

123

124

125

126

independent populations drawn from the 3 dominant racial groups on earth: three Caucasian

populations (Austria, Lithuania and UK), three Asian populations (China, Iran and Mauritius)

and four African populations (Kenya, Morocco, Nigeria and Senegal). Caucasian, Africans and

Asians together represent $91.4 \%$ of the current total world population

(http://www.geohive.com/earth/world1.aspx). We found that females with lower body fatness

(BMI and $\mathrm{BF} \%$ ) were rated as more attractive in all societies. WHR was also a significant factor

that was more important (greater $r^{2}$ ) in African populations. Deviations from the evolutionary

model were probably because raters used BMI as a proxy for subject's age.

\section{Methods}

\section{Evolutionary model}

We considered that variation in female body fatness might have important fitness

consequences for three different reasons: risk of fatal disease, impacts on fecundity, and survival

under famine conditions. We searched the literature for epidemiological studies which had

related the risks of mortality due to various individual fatal diseases, and all-cause mortality, to

individual differences in body fatness. In addition we also sought studies that had linked together

variations in body fatness and fertility. The thrifty gene hypothesis, first developed in the 1960s

(Neel 1962) with respect to diabetes, and subsequently elaborated in the context of obesity 
127 (Eknoyan 2001; Lev-Ran 2001), suggests that we have a genetic predisposition to obesity

128 because in our evolutionary history we were regularly exposed to periods of famine. Individuals

129 carrying 'thrifty genes', favouring the efficient deposition of fat reserves in the intervals between

130 famines, would therefore be selected because they would have a greater chance of surviving the

131 next famine. Body fatness is therefore an advantageous trait with respect to famine survival (but

132 see Speakman 2007; 2008). Interestingly, in this context males who are more hungry alter their

133 ratings of female attractiveness towards fatter subjects (Swami \& Tovee 2006). The exact

134 relationship between survival in the absence of food and body fatness has been the subject of

135 several mathematical models (Hall 2012; Song \& Thomas 2007; Speakman \& Westerterp 2013).

136 We used the outputs of such models to predict the shape of the relationship between body fatness

137 and famine survival, and hence mortality risk (1/survival). We then combined these different

138 impacts of body fatness on mortality, to produce two anticipated relationships between fatness

139 and fitness: one including the effects of famine and one excluding such effects.

141 Female body images

142 We used a series of 21 soft tissue dual-energy x-ray absorptiometry (DXA) images. DXA is a

143 technique for evaluating body composition using the fact that bone, fat and lean tissue

144 differentially absorb x-rays at different frequencies. The images we used had been previously

145 used (Faries \& Bartholomew 2012) to study the role of fatness in the perception of physical

146 attractiveness in US college students. The 21 female body images covered 7 levels of body fat

147

percentage (BF \%): 15\%-20\%, 21\%-25\%, 26\%-30\%, 31\%-35\%, 36\%-40\%,41\%-45\%, and 46\%- 
$14850 \%$. At each level of BF\% there were 3 levels of WHR: low (0.60-0.66), mid (0.67-0.75), and

149 high (0.76-0.88) respectively. The BMI ranged from 19 to $40 \mathrm{~kg} \cdot \mathrm{m}^{-2}$. These images were

150 selected from a database of over 5000 female images and were specifically selected to break any

151 correlation of BF\% to WHR(Faries \& Bartholomew 2012). There was consequently a non-

152 significant correlation the two variables in these images $\left(\mathrm{r}^{2}=0.029, \mathrm{p}>.05\right.$, for full details of the

153 images and their characteristics see (Faries \& Bartholomew 2012). We could not use a wider

154 range of body fatness because it was not possible to find images with higher or lower BMI with

155 also the desired range of WHR. The range we used spanned all the predicted peaks in the

156 relationship between BMI and fitness derived from the evolutionary models.

157 Ages of the subjects in the images were known, but not controlled for, or revealed to the raters.

158 By using DXA images the facial details were not a factor influencing the subjects' judgment of

159 attractiveness. Two of the images showing a constant level of WHR at two very different levels

160 of body fatness are shown in supplementary materials (Fig. S1). For the present study, the

161 images were printed on an A3 sheet of heavy paper and the individual images were then cut out

162 into playing card sized rectangles. The number of the image (1 to 21) (Faries \& Bartholomew

163 2012) was written on the back of each card.

164

165 Participants

166 Participants ( $\mathrm{N}=1327$ in total) were recruited from major cities in ten countries. In detail these

167 were Graz in Austria, Panevezys in Lithuania, Aberdeen in the UK, Beijing in China; Tehran in

168 Iran, Port Louis in Mauritius, Eldoret in Kenya, Tiflet, Kenitra, Casablanca, Rabat and Oujda in 
169 Morocco, Umuahia, Abia state, in Nigeria, and Dakar in Senegal (Table 1). Participation was

170 voluntary and verbal informed consent was obtained before the study. All the procedures for the

171 overall study were ethically reviewed and approved by the Chinese Academy of

172 Sciences, Institute of Genetics and Developmental Biology Institutional review board (IGDB-

173 2013-IRB-005). In addition, local ethical approval was also obtained at the UK site from the

174 University of Aberdeen college of life science and medicine ethical review board

$175(\mathrm{CERB} / 2014 / 12 / 1123)$.

176

177 Procedure

178 Participants (raters) were asked for some basic information (age, sex, ethnicity, height, weight)

179 before the task started. They were then given the 21 image cards which were shuffled and placed

180 on a table in front of them in a random order. Participants were then asked to reorder the cards

181 from the most attractive on their right to the least attractive on their left. They were not allowed

182 to have ties. The sorting task took about 5 minutes to complete.

183 The recorder then recorded the order of the images and confirmed with the subject that the order

184 was indeed from least to most attractive and not the reverse. We predominantly selected subjects

185 in the age range 18 to 50, except in Mauritius where the subjects were adolescents (Table 1). The

186 populations varied significantly in their mean BMI (Table 1). We did not exclude anyone

187 according to their sexual orientation. Homosexuality is illegal or highly stigmatized in several of

188 the countries involved in the study and we therefore did not consider that self reports of sexual

189 orientation would be reliable. We also did not control rater hunger or stress levels both of which 
have been previously implicated as influencing ratings of female attractiveness (Swami \& Tovee 2006; Swami \& Tovee 2012).

Bartholomew 2012). In that study individuals were asked to select their most and least attractive

images from the set and give them ratings of 9 and 1 respectively and then use these anchors to grade all the other images on a scale from 1 to 9 . In this process it was possible to get ties. To evaluate whether the resultant ratings were similar across the two methodologies we also applied this procedure to the subjects in the UK. There was a very strong correlation $\left(\mathrm{r}^{2}=0.95\right)$ in the ratings of the images between the two protocols lending confidence to the fact we could directly compare our data to those collected previously in the USA, despite the slight protocol difference.

\section{Standard Score}

The rank positions of the images were converted to a score in the range 1 to 9 . The score followed the formula $a_{n}=1+(n-1) * 0.4$ (where $n$ was the rank order of the image from the least attractive to the most attractive i.e., $\mathrm{n}$ of the least attractive image was 1 so the score was $\mathrm{a}_{1}=1+$ $(1-1) * 0.4=1$ and the most attractive image was 21 so the score was $a_{21}=1+(21-1) * 0.4=9$ )

\section{Age ratings}

Participants $(\mathrm{N}=325$, from Austria, China, Iran, Kenya, Morocco and Senegal) took part in this task. Raters were asked for some basic information (age, sex, ethnicity, height, weight) before the task started. They were given the same 21 images on an A4 paper with a separate list of the 
211 actual ages of the subjects in the images ( 21 images with 21 ages). They were asked to match

212 together the age and the image. The task took about 5 minutes to complete.

214 Statistical analysis

215 Software including R, SPSS 11.5 and Minitab 16 were used to analyze data. Pearson

216 correlation was used to explore the overall correlation of the rankings between the sexes of the

217 raters. In addition we compared the ratings of female and male raters for all the images

218 individually in each country (corrected for multiple testing in each country using the Bonferroni

219 correction) using the non-parametric Mann Whitney test as data were often not normally

220 distributed. We performed univariate analyses using mean attractiveness across all the raters and

$221 \% \mathrm{BF}, \mathrm{BMI}$ or WHR as predictors in least squares linear regression analysis for each country

222 separately. We then performed analyses using general linear modeling with mean attractiveness

223 across all raters as the dependent variable, and the picture $\mathrm{BF} \%, \mathrm{BF} \%$-squared, WHR and age

224 and all the two way interactions as fixed factors. Analyses were conducted separately for each

225 country. Mathematical modeling and analysis was performed in Mathcad 15.

226 Results

227 Evolutionary model of the relationship between attractiveness and fatness

228 Many studies have associated the risk of developing various diseases with different levels of

229 body fatness (Borugian et al. 2003; Chan et al. 1994; Despres 2012; Terry et al. 1992). We found

230 three reviews which compiled data for different ethnic groups to establish ethnic specific patterns

231 of mortality in relation to fatness. These included reviews involving $>900 \mathrm{k}$ Caucasians 
232 (Whitlock et al. 2009) and >1.1Million Asians (Zheng et al. 2011). We could not locate any

233 summary of the same relationship pertaining to Africans living in Africa, but found reviews

234 including >360k African Americans (Cohen et al. 2014; Cohen et al. 2012; Flegal et al. 2013). In

235 the studies involving Caucasians and African Americans the data was subdivided by gender so

236 we could extract female specific curves, but for the Asians this was not possible from the data in

237 the original paper. However, the patterns for males and females in the Caucasians and African

238 Americans were almost identical so this is unlikely to be a serious source of error. The pattern of

239 all cause mortality (total mortality irrespective of cause) from these three studies in relation to

240 BMI is shown in Fig. 1A. We expressed the mortality in each BMI class as the excess mortality

241 above that of the lowest BMI class, since this reflects the negative impact of differences in body

242 fatness, and then fitted a polynomial to the data for each ethnic group using ordinary least

243 squares regression. The resultant best fit (least squares) equations were a series of third order

244 polynomials which explained respectively $97.1 \%$ for Caucasians (eqn 1.1), 99.8\% for Asians

245 (eqn 1.2) and 98.4\% for African Americans (eqn 1.3), of the variance in excess annual mortality 246

247

$248 \mathrm{y}_{1 \mathrm{a}}=-0.0034 \mathrm{x}^{3}+0.3286 \mathrm{x}^{2}-10.004 \mathrm{x}+97.859$

(eqn 1.1)

$y_{1 c}=-0.002359 x^{3}+0.24392 x^{2}-7.6714 x+76.089$

(eqn 1.2)

$249 \mathrm{y}_{1 \mathrm{aa}}=-0.0005 \mathrm{x}^{3}+0.0649 \mathrm{x}^{2}-2.2071 \mathrm{x}+23.272$

(eqn 1.3)

251 Where $\mathrm{y}_{1 \mathrm{c}}, y_{1 a}, y_{1 a a}$ are the excess annual mortalities per thousand population due to all causes

252 and $\mathrm{x}$ is the BMI for Caucasian, Asian and African American populations respectively. Many 
253

254

255

256

257

258

259

260

261

262

263

264

265

266

267

268

269

270

271

272

$y_{3}=0.0478 x^{2}-2.2438 x+26.282$

$y_{2}=0.1065 x^{2}-4.6346 . x+50.145$

(2)

of the variation

described by a second order polynomial (eqn 2)

studies have also studied aspects of reproductive biology in relation to body fatness (or BMI).

However, we could not find any summaries for Asian or African/African American populations.

Among the most comprehensive studies of Caucasians was the Adventist Health study(Jacobsen

et al. 2013) which included lifetime fertility records for 33,159 females along with their BMI at

age 20. The relationship between the probability of having no children during a reproductive life

of 20 years, and BMI class at age 20 is shown in Fig. 1B. The 20 year excess probability of not

having children, compared to the BMI class with the lowest rate of nulliparity, contributes to the

negative effect of BMI on fertility. To obtain the annualized rate of excess 'missing births' we

divided this lifetime rate by 20 and then fitted a polynomial to these data using ordinary least

squares regression. In this case the best fit was a second order polynomial which explained 97.5\%

The same study also showed that the probability of having a second child was also impacted by

obesity status at age 20 . The data are also shown in Fig. $1 \mathrm{~B}$ and in this case the excess missing

births relative to the BMI class with the lowest rate of not having a second child were best 
274 which explained $95.9 \%$ of the variation.

275 Given the similarity in the relationships between mortality and BMI among the different ethnic

276 populations we assumed that the relationships between BMI and fecundity for all ethnic groups

277 were adequately represented by these Caucasian data. Hence the combined effects of fatness on

278 all cause mortality and reduced fecundity can be expressed as

$279 \mathrm{y}_{\text {total }}=\mathrm{y}_{1}+\mathrm{y}_{2}+\mathrm{y}_{3}$

280 Substituting from eqns 1 to 3 into 4, collecting terms and simplifying yield three ethnic specific

281 relationships for Caucasians, Asians and African Americans.

282

$283 \mathrm{y}_{\text {totalc }}=-0.00236 \mathrm{x}^{3}+0.3982 \mathrm{x}^{2}-14.550 \mathrm{x}+152.52$

$284 \mathrm{y}_{\text {totala }}=-0.00034 \mathrm{x}^{3}+0.4829 \mathrm{x}^{2}-16.8824 \mathrm{x}+171.286$

285

$y_{\text {totalaa }}=-0.0005 x^{3}+0.2192 x^{2}-9.0855 x+99.70$

287 This composite curves expressing total excess mortality and reduced fecundity are shown in Fig.

288 1C. Differentiating equations 5.1 to 5.3 gives

289

$290 \frac{\mathrm{dy}}{\mathrm{dx}}=-0.00708 \mathrm{x}^{2}+0.7964 \mathrm{x}-14.9498$

(eqn 6.1)

$291 \frac{\mathrm{dy}}{\mathrm{dx}}=-0.0102 \mathrm{x}^{2}+0.9658 \mathrm{x}-16.8824$

(eqn 6.2)

$292 \frac{\mathrm{dy}}{\mathrm{dx}}=-0.0015 \mathrm{x}^{2}+0.4384 \mathrm{x}-9.0855$

294 We can then solve these quadratic equations 6.1 to $6.3 \mathrm{f}(\mathrm{x})=0$ to obtain the BMI at the 
295

296

297

298

299

300

301

302

303

304

305

306

307

308

309

310

311

312

\section{9} 14

minimum point and this yields

$0=0.00708(x-88.673)(x-23.182)$

$0=0.0102(x-71.554)(x-23.131)$

$0=0.0015(x-269.818)(x-22.448)$ (eqn 7.1)

(eqn 7.2)

(eqn 7.3)

Each of which has only one solution in the range BMI 15 to 40 which is 23.182 for Caucasians,

23.131 for Asians and 22.448 for African Americans. Therefore the BMI at the peak of the

fitness function (lowest mortality) was between 22.448 and 23.182 depending on ethnicity. This

model predicts therefore that if attractiveness is directly related to fitness, combining future

potential fertility with all cause mortality, the relationship between attractiveness and BMI

should have a peaked function, with the maximum attractiveness at a BMI around 22.4 to 23.2.

Given the shape of the function in Fig. $1 \mathrm{C}$ we would expect the attractiveness function to be similarly distributed about this peak.

During famine all mortality may be considered 'excess mortality'. We previously (Speakman \&

Westerterp 2013) constructed a mathematical model of energy utilization during complete

starvation to predict the survival durations of people at different starting body fatness (or BMI).

This model is not dependent on the race of the individual. For females the survival function was

15 Survival (days) $=12.306 \times-180.1$

(eqn 8) 
316 Since mortality risk is the inverse of survival duration we can express the excess mortality per

317 thousand population as

$318 \quad \mathrm{y}_{4}=\frac{1000}{(12.306 \cdot x-180.1)}$

(eqn 9)

319

320 And hence adding $\mathrm{y}_{4}$ to the ethnic specific estimates of $\mathrm{y}_{\text {total }}$ gives the total estimated mortality

321 risk including famine mortality for each race (Caucasian: 10.1, Asians 10.2 and African

322 Americans 10.3) as

323

$324 \mathrm{y}_{\text {totalc }}=-0.002359 \mathrm{x}^{3}+0.39822 \mathrm{x}^{2}-14.5498 \mathrm{x}+152.516+\frac{1000}{(12.306 . x-180.1)} \quad($ eqn 10.1$)$

$325 \mathrm{y}_{\text {total a }}=-0.00034 \mathrm{x}^{3} \quad+0.4829 \mathrm{x}^{2}-16.8824 \mathrm{x}+171.286+\frac{1000}{(12.306 . x-180.1)} \quad$ (eqn 10.2)

$326 \mathrm{y}_{\text {total aa }}=-0.0005 \mathrm{x}^{3} \quad+0.2192 \mathrm{x}^{2}-9.0855 \mathrm{x}+99.70+\frac{1000}{(12.306 . x-180.1)} \quad($ eqn 10.3$)$

328 The curve relating mortality to BMI represented by equations 10.1 to 10.3 are shown in Fig. 1D.

329 Differentiating equations 10.1 to 10.3 yields

330

$331 \frac{\mathrm{dy}}{\mathrm{dx}}=-0.00708 \mathrm{x}^{2}-0.7964 \mathrm{x}-14.9498+\frac{12306}{(12.306 \mathrm{x}-180.1)^{2}}$

$332 \frac{\mathrm{dy}}{\mathrm{dx}}=-0.0102 \mathrm{x}^{2}+0.9658 \mathrm{x}-16.8824+\frac{12306}{(12.306 \mathrm{x}-180.1)^{2}}$

$333 \frac{d y}{d x}=-0.0015 x^{2}+0.4384 x-9.0855+\frac{12306}{(12.306 x-180.1)^{2}}$

335 and solving equations 11 for $\mathrm{f}^{\prime}(\mathrm{x})=0$ gives a single root for each ethnic group: Caucasians (eqn

336 11.1) $\mathrm{x}=24.78$, Asians (eqn 11.2) $\mathrm{x}=24.72$ and African Americans (eqn 11.3) $\mathrm{x}=24.05$. Hence 
including mortality due to famine into the prediction shifts the peak upwards and strongly

accentuates the negative aspects of being leaner than this optimum. If attractiveness is related to

fitness the actual curve relating attractiveness to body fatness might be expected to lie

somewhere between the inverses of the curves depicted in Fig. 1C and 1D, depending on the

perceived risk in a given population that there will be a famine. This might for example depend

on the duration since the last famine occurred in a given population.

Comparison of ratings of female physical attractiveness by males and females

To investigate the influence of rater sex on perceived attractiveness we performed the study

using both sexes as raters. Scatter plots of the average attractiveness rating of females rater

against male raters for the 21 images in each of the nine populations [excluding Senegal where

all the participants were female] showed that there was strong concordance in the perceptions of

female attractiveness between the sexes in all populations (UK: $R^{2}=0.9778$; China: $R^{2}=0.99$; Iran:

$R^{2}=0.9888$; Mauritius, $R^{2}=0.97$; Kenya: $R^{2}=0.9791$; Morocco $R^{2}=0.9906$; Nigeria: $R^{2}=0.9428$ )

(Fig. 2). We also explored whether individual images were rated differently. There were no

significant differences between female and male raters at the 95\% confidence level (Bonferroni corrected for 188 tests) for all of the images across nine countries (Table S1). Although there

was no overall effect when using the Bonferroni correction, we noted an interesting pattern in the unadjusted probability values. Among the Caucasian populations only 1/62 tests showed a significant difference in the ratings between males and females. In the Asian populations 9/63 
ratings between males and females. Hence, while there was no overall effect using the adjusted values, it is possible there were ethnic differences in the extent to which males and females agreed on the attractiveness of particular images, and the use of the Bonferroni correction was too stringent to allow us to detect this effect.

Effects of BF\% and WHR: univariate analyses

Scatter plots of female attractiveness in relation to BF\% (Fig. 3) BMI (Fig. S2) and WHR (Fig. 4) were generated for each country and univariate analyses performed. We found a significant negative linear relationship between $\mathrm{BF} \%$ and attractiveness in all the populations. Parameters of the univariate regression models are in Table 2. Across all the populations the linear fit models explained between 46.3 and $85.3 \%$ of the variance in attractiveness. The poorest fits were for Nigeria and Senegal. Including BF\% squared did not result in a significant improvement in any of the relationships. The pattern for BMI was almost identical (Fig. S2). In none of the populations did a peaked relationship fit the data, contrary to what was predicted $a$ priori from the evolutionary model (Fig 1).

WHR also showed a linear relationship to attractiveness rating (Fig. 4) but in this instance the fits were much poorer than for $\mathrm{BF} \%$ or $\mathrm{BMI}$ (Table 2) and for all three of the Asian countries WHR was not significantly associated with attractiveness ( $>$ >05).

\section{Multiple regressionanalyses}

None of the two way interactions between BF\%, WHR and age were significant and these terms were removed from the final models. When BF\%, WHR and age were included as 
independent predictors they all entered as significant predictors $(\mathrm{P}<.01)$ in all countries except Mauritius ( $\mathrm{P}=0.028$ : not significant at $\mathrm{P}=.05$ when corrected for multiple testing). This occurred even though in the other Asian countries WHR had not been significant in the univariate analysis (above). In Mauritius only BF\% was a significant predictor. BF\%-squared was not a significant term in any of the models. Age of the subjects in the images was also a significant predictor $(\mathrm{P}<0.05)$ except in Austria $(\mathrm{P}=0.129)$ and $\mathrm{UK}(\mathrm{P}=0.059)$ (Table 3), despite the images containing no overt indication of the subject age. Parameters of the fitted multiple regression models are presented in Table 3.

Age relationship to $B F \%$ and $B M I$

There was no significant correlation between the estimated age of the figures and their actual ages across all 6 populations involved in this part of the study (Fig. 5A). However, there was a strong positive relationship between estimated age and $\mathrm{BF} \%\left(\mathrm{r}^{2}=0.812\right)$ (Fig. $\left.5 \mathrm{~B}\right)$ and between estimated age and BMI $\left(\mathrm{r}^{2}=0.848\right)$ (Fig. 5C). There was also no significant relationship between estimated age and WHR (Fig. 5D).

\section{Discussion}

\section{Ratings by males $v$ females}

Several previous studies have compared the ratings made by males and females of female attractiveness. Similar to the results from our study, in most previous studies it was observed that males and females in a given population did not differ in their ratings of female attractiveness (Faries \& Bartholomew 2012; Furnham et al. 1997; Henss 1995; Henss 2000; Kościński 2013; 
400 Schmalt 2006; Singh 1994; Streeter \& McBurney 2003; Swami et al. 2006a; Swami \& Tovee

401 2005; Tassinary \& Hansen 1998; Tovée et al. 2006; Tovee \& Cornelissen 2001; Tovee et al.

402 2002). This was despite sometimes large differences in what the different populations perceived

403 as attractive (see in particular (Tovée et al. 2006)). In contrast some studies have found that

404 females rated attractiveness differently from males with respect to WHR (Furnham et al. 1998).

405 The reasons for differences between studies are unclear Perhaps it is evolutionarily advantageous

406 for males and females to perceive attractiveness in their own populations in the same way, and

407 most studies including ours indicate this is the case. However, we did note that males and

408 females were more likely to make divergent estimates of attractiveness of given images in Asian

409 and African populations relative to Caucasians. The reason for this ethnic difference is unclear.

\section{Body fatness $v$. waist to hip ratio}

411 Early studies regarding the relationship between female body shape and physical attractiveness

412 placed considerable emphasis on the role played by WHR (Henss 2000; Mo et al. 2014; Price et

413 al. 2013; Singh 1993; Singh 1994; Singh 1995b; Tassinary \& Hansen 1998; Tovee et al. 2002).

414 These studies suggested an optimal WHR of around 0.7 was maximally physically attractive

415 (Dixson et al. 2007; Marlowe \& Wetsman 2001). This was consistent with the fact that playboy

416 centerfolds and glamour models almost all having WHRs between 0.6 and 0.7 (Katzmarzyk \&

417 Davis 2001; Voracek \& Fisher 2002) and this changed only very slightly over the 5 decades from

4181950 to 2000. Moreover, when individuals are asked to manipulate graphics to generate their

419 ideal body shape, they routinely select a WHR of 0.7 (females) to 0.73 (males) (Crossley et al.

420

2012). Surgical enhancement of WHR increases physical ratings of attractiveness (Dixson et al. 
421

422

423

424

425

426

2007). WHR was interpreted within an evolutionary context as of importance because it was suggested to be an honest signal of health and fertility (Bigaard et al. 2004; Singh 1995a; Wass et al. 1997) or cognitive ability (Lassek and Gualin, 2008). An early suggestion that females with higher WHR might have more sons was later dismissed (Tovee et al. 2001).

.

However, it was pointed out in the late 1990s and early 2000's that WHR is not independent of body fatness, which could itself act as an honest signal of health and fertility (Tovee \& Cornelissen 1999; Tovee et al. 1999; Tovee et al. 1998) and hence be the primary signal indicating female attractiveness (Tovee et al. 1999; Tovee et al. 1998). Since this time a large number of studies have attempted to partition the variation in physical attractiveness that is explained by body fatness (or body mass index) and WHR. These studies showed conclusively, across many cultures, that variation in BMI was a better indicator of physical attractiveness than WHR(Kościński 2013; Swami et al. 2006a; Swami \& Tovee 2005; Tovée et al. 2006; Tovee \& Cornelissen 2001; Tovee et al. 2002; Tovee et al. 1999; Tovee et al. 1998). This was true even when the variation in the two traits was held constant, (Swami et al. 2006a; Swami \& Tovee 2005; Tovée et al. 2006; Tovee et al. 2002) or the relationship between BMI and WHR was made artificially negative (Tovee et al. 1999) .

Our own study confirms this general pattern that body fatness explains more of the variation in physical attractiveness than does WHR. In contrast to many previous studies however, the relative importance of body fatness and WHR in our data was culturally dependent. In the univariate analysis the variance explained by body fatness was considerably greater in the Asian 
442 and Caucasian populations ( 75 to $85 \%$ ) than in the four African populations (46 to $75 \%$ ).

443 Moreover, in the univariate analysis there was no significant effect of WHR in the three Asian

444 populations, but in the African populations the explained variation by WHR alone was 25 to $32 \%$.

445 A previous study using the same images rated by a predominantly Caucasian population (70\%

446 Caucasian) in the USA found $70 \%$ of the variance was explained by body fatness and $18 \%$ by

447 WHR (Faries \& Bartholomew 2012) consistent with the $76 \%$ and $21.9 \%$ respectively for the

448 Caucasian UK sample and the $77 \%$ and $17 \%$ respectively in Lithuanians measured here. The

449 very high percentage variation explained by body fatness (BMI) and the low variation explained

450 by WHR in the Asian populations was consistent with the variation in attractiveness explained

451 by BMI and WHR in Malaysians (Swami \& Tovee 2005) and Thai subjects (Swami \& Tovée

452 2007), but in Japanese subjects the variance explained by WHR was higher at 30.2\% (Swami et

453 al. 2006a). Previous studies of Caucasians have also reported high levels of variation explained

454 by BMI: 84.1\% (Tovée et al. 2006), 83.3\% (Swami et al. 2006a), 76.8\% (Swami \& Tovée

455 2007),73.7\% (Tovee et al. 1999), 73.5\% (Tovee et al. 1998), 70.3 to 73.3\% (Swami \& Tovée

456 2007), although using 3D rotating images the impact of BMI was lower at 53\% (Smith et al.

457 2007). This range of values for $2 \mathrm{D}$ images covers the data reported here. Consistent with our

458 work, previousmultiple regression analyses of rated attractiveness of the female body using

459 digitally manufactured stimuli suggested that BMI was twice as important as WHR for the rated

460 attractiveness in Poland (Kościński 2012; Kościński 2013; Kościński 2014)..

461

462 Few previous studies of the impact of body fatness and WHR have been conducted in 
463

464

465

466

467

468

469

470

471

472

473

474

475

476

477

478

479

480

481

482

483

African populations. In contrast to our data, $82.5 \%$ of the variance in attractiveness was

explained by BMI and only 7.5\% by WHR in South African Zulus (Tovée et al. 2006), which

suggested African populations do not differ from Caucasians and Asians. In contrast, we found

much lower \% explained variation by body fat and a much greater role for WHR in all four of

the African populations in our sample. In fact, in the sample from Nigeria, WHR was more significant than BMI in the multiple regression analyses. The greater role for WHR in the four African populations is consistent with previous studies that have suggested a preference for a more extreme low WHR in African populations (Furnham et al. 2002) and a preference for a lower WHR among African Americans compared to US Caucasians (Freedman et al. 2007;

Freedman et al. 2004). The reason why WHR may play a greater role in African populations is presently unclear. One potential factor maybe the role of the buttocks in assessments of physical attractiveness among Africans (Marlowe et al. 2005) and African Americans (Cunningham et al. 1995). This ethnic difference is apparent in the differences in ethnic ideals with respect to buttock augmentation surgery (Roberts III et al. 2006) in which Asians prefer very small and African Americans very large buttocks. This difference may accentuate the importance of WHR in attractiveness ratings by African populations.

In addition, there are ethnic differences in the reported consequences of obesity for various health related parameters. For example, obese African Americans show much greater risk of developing insulin resistance and diabetes than either Caucasians or Hispanics, as they become obese, but Hispanics show a much greater risk of hepatic steatosis (Speakman \& Goran 2010). It is potentially the case that WHR provides a much better signal of health in Africans than in other 
populations.

\section{Evolutionary aspects and optimal BMI}

Many previous studies have set the observations that raters prefer women with given WHRs and BMIs into a post hoc evolutionary context by suggesting that BMI and WHR are honest signals of both health and fertility (Bigaard et al. 2004; Singh 1995a; Wass et al. 1997). Few studies, however, have attempted to rigorously test this suggestion by comparing the actual pattern of variation in attractiveness, as a function of fatness or WHR, to that expected a priori on the basis of epidemiological data on the relationships between fatness, health and fertility. We attempted to fill this gap by constructing a mathematical model relating fatness to future mortality risk (incorporating both health and fertility effects) using data from several large epidemiological studies that have related BMI to all cause mortality in Caucasians (Whitlock et al. 2009), Asians (Zheng et al. 2011) and African Americans (Cohen et al. 2014; Cohen et al. 2012; Flegal et al. 2013) and BMI at age 20 to future reproductive success in over 33,000 females Caucasians (Jacobsen et al. 2013). Factoring these two effects into the model suggested the optimal female BMI should be around 22.4 to 23.2. A limitation of our study is that we could not find data on the link of mortality to BMI for Africans living in Africa, for which we substituted data on African Americans, and we could only find fecundity data based on a large sample size for

Caucasians. The similarity of the mortality patterns between Caucasians, Asians and African Americans (Fig 1A), however, lends some confidence that ethnic effects on these relationships are relatively small and the derived optima are probably appropriate for the populations we 
505

506

studied. An additional potential factor is that body fat stores may provide a resource base to ensure survival during periods of famine (the thrifty gene hypothesis). Using a previous mathematical model relating famine survival to fat storage (Speakman \& Westerterp 2013) we predicted that if famine mitigation was also important the optimum BMI might rise slightly to between 24.0 and 24.8 but the shape of the curve relating attractiveness to body fatness would be more steeply negative at lower levels of body fatness (Fig. 1D).

This predicted peaked relationship between body fatness and physical attractiveness with a maximum attractiveness around a BMI of 22.4 to 24.8 was not supported by the data we collected in any population. Over the range of BMIs that we studied (19 to 40) there was a negative linear between attractiveness and BMI (Fig. S2). This range is adequate to detect a peak, if such existed, at the position we predicted. In none of the populations over this BMI range was there any indication of a peak in the relationship (as judged by the significance of adding additional polynomial terms to the regression model). Similar to our data, a linear negative relationship between BMI and physical attractiveness was observed previously over the BMI range 18 to 26 (Swami \& Tovée 2007), and a linear negative relationship was observed between attractiveness and body fatness over a range from 20 to $35 \%$ body fat (Smith et al. 2007). Using the same image set as used here Fairies and Batholomew (Faries \& Bartholomew 2012) also reported a linear negative relationship between attractiveness and BMI rated by US college students of mixed ethnicity.

Hence, if there was a peak physical attractiveness, in all ten of the populations we studied the 
526

527

528

529

530

531

532

peak was at least as low as $\mathrm{BMI}=19$ and potentially lower. This was consequently at least 3.5

BMI units below the predictions of the evolutionary model. For an average height woman

$(1.55 \mathrm{~m})$ the difference between the predicted and observed maximum was at least $10 \mathrm{~kg}$ of body weight. This is an enormous difference in body weight and based on these data we can clearly reject the evolutionary models, as formulated, based on health, fertility and famine survival. We did not have more extreme body compositions included into the images presented to the raters, and hence there might be a maximum attractiveness at a lower BMI than the lowest BMI in our image set. In fact data from previous studies suggest that there may be a peak in the relationship between BMI and attractiveness (Swami et al. 2006a; Swami \& Tovée 2007; Tovée et al. 2006; Tovee et al. 1999; Tovee et al. 1998) at a BMI around 18 to 20. In all these cases the authors fitted a 3 term polynomial with WHR as an additional term, but in only one study were actual coefficients reported in the publication. Hence it was not possible to explicitly solve the equations to locate the peak. We consequently recoded the data from the plots presented in the figures (using the software package Data-thief) and fitted our own curves to the data and then solved these curves for the maxima by differentiating them and solving them for $\mathrm{f}^{\prime}(\mathrm{x})=0$ (Table 4). This reanalysis of previously published data clearly shows that for most populations the maximal physical attractiveness occurred at a BMI between 18.4 and 21.4 (mean of all studies excluding $2 \mathrm{~b}$ and $4 \mathrm{~b}$ in Table $4=20.152, \mathrm{sd}=1.012, \mathrm{n}=7$ ). The two excluded studies are discussed below. This mean peak attractiveness sits 2.4 to 4.6 BMI units below the prediction (about 9 to $16.5 \mathrm{~kg}$ for an average height woman). This estimated peak attractiveness at a BMI at 18.4 to 21.4 is consistent with many other data. For example, the BMIs of playboy centerfolds 
547 and glamour models over the last 50 years are almost all in the range 17 to 20 (Katzmarzyk \&

548 Davis 2001; Tovee et al. 1999; Voracek \& Fisher 2002). Women and men asked to manipulate

549 female 3D computer models to make them maximally attractive make them have BMIs of 18.9

550 and 18.8 respectively (Crossley et al. 2012). The biggest outlier in previous studies of

551 attractiveness at low BMI was the observation that in Poland the highest rated attractiveness was

552 at a BMI of 15 (Kościński 2013), and potentially lower as this was the smallest stimulus in the 553 set presented.

554

Why do the data for these modern societies seem to deviate so widely from the evolutionary

model predictions about the most attractive level of body fatness? One potential interpretation is

that the populations studied here are all exposed to the same western media which promotes a

thin female body ideal (Groesz et al. 2002; Posavac et al. 1998). It is difficult however to

separate cause and effect. Does media exposure drive people's perceptions of attractiveness? Or

is the 'thin ideal' in the media simply reflecting what people already see as attractive? The fact

the populations differed significantly in their perceptions of the importance of WHR suggests

that in fact their opinions are not all homogenized by exposure to the same western media images

of what is attractive. The data were not consistent with the suggestion that people are attracted to

averageness in their own population (Koscinski 2012) since the universal preference for low

BMI contrasted the much higher and more variable levels of average BMI among the rating 
568

569

570

571

572

A potential problem with studies such as ours, and all previous studies of the role of BMI or body fatness, based on $2 \mathrm{D}$ images or $3 \mathrm{D}$ models, is that the people making the ratings are given no instructions about the age of the subjects. Body fatness and BMI are both strongly related to age (Speakman \& Westerterp 2010) as to a lesser extent is WHR (Marlowe et al. 2005). Hence, individuals rating the images may be using BMI as a proxy to estimate the age of the subjects.

Our observers were definitely sensitive to the ages of the individuals in the pictures, despite there being no immediately obvious way they could tell their ages. Were they also using BMI as a cue to the age of the subjects? There was some evidence to support this hypothesis. When individuals matched up the models ages to their pictures, there was a strong association between the estimated age and both BF\% and BMI but not to their actual ages (Fig 5). This suggests that people viewing the images used body fatness to estimate the age of the subjects. In the evolutionary model of the impact of fatness and fertility we assumed that age and BMI were independent. However, fertility is strongly dependent on age, in part because of the declining ovarian reserve as a function of age (Wallace \& Kelsey 2010). However, fertility reaches a peak in the late teens and early 20 's because prior to age 20 there is an increased risk of annovulatory cycles. The relationship between infertility and age based on literature data for Caucasians (Henry 1961; Leridon 1978; Leridon 2008; Menken \& Larsen 1986; Pittenger 1973; Trussell \& Wilson 1985; Vincent 1950) is shown in Fig. S3 and a $4^{\text {th }}$ order polynomial explained $98.3 \%$ of the variation in infertility. The best fit equation was 
588

589

590

591

592

593

594

595

596

597

598

599

600

601

602

603

604

605

606

607

608

$y_{5}=0.0052 A^{4}-0.6164 A^{3}+27.105 A^{2}-514.95 A+3558.1$

(eqn 12)

Where $\mathrm{y}_{5}$ is the age related infertility per thousand population, and $\mathrm{A}$ is the age. Given the relationship between BMI and estimated age of the subjects (Fig 5) we can use the derived fitted relationship

$\mathrm{A}=0.027 x^{2}+3.1717 x-30.599$

eqn 13

where $\mathrm{x}$ is the BMI, to derive the expected relationship between BMI and mortality risk if BMI is used only as a proxy for age. Substituting eqn 13 into equation 12 gives

5

$\mathrm{y}_{5}=0.0052\left(0.027 x^{2}+3.1717 x-30.599\right)^{4}-0.6164\left(0.027 x^{2}+3.1717 x-30.599\right)^{3}+27.105\left(0.027 x^{2}\right.$

$+3.1717 x-30.599)^{2}-996.68 x+12495.57 \quad$ eqn 14

Differentiating eqn 14 gives

$\frac{d y}{d x}=0.0208\left(0.027 x^{2}+3.1717 x-30.599\right)^{3}-1.8492\left(0.027 x^{2}+3.1717 x-30.599\right)^{2}+$

$1.4637 x^{2}+171.94 x-2655.45$

Expanding the brackets and collecting terms gives the $6^{\text {th }}$ order polynomial

$\frac{\mathrm{dy}}{\mathrm{dx}}=0.000000409 \mathrm{x}^{6}+0.0001445 x^{5}+0.01421 x^{4}+0.019753 x^{3}-31.793 x^{2}+716.18 x-3790.53$

eqn 15

And solving eqn 15 for $f(x)=0$ gives a single root in the range 16 to 50 at $x=17.41$.. Although, this is significantly lower than the mean peak attractiveness of 20.15 across the studies in Table 4 (one sample t-test $=7.17, \mathrm{p}<0.001$ ), the local minimum at 17.41 is very shallow and there is very little difference over the range from 16 to 21 , which encompasses most of the maxima in attractiveness in the studies summarized in Table 4. This analysis suggests that the shape of the 
609

610

611

612

613

614

615

616

617

618

619

620

621

\section{8}

relationship between BMI and physical attractiveness may come about primarily because subjects in such experiments use BMI as an indicator of subject age, and then attractiveness is primarily gauged on the evolutionary significance of the estimated age. The strong link of age to fertility results in subjects rating the pictures with BMIs around 20 as most attractive because they would be aged 19 to 22 and hence most fertile. Additional factors such as health relationships to BMI and the role of famine, and indeed the effects of BMI at a fixed age on fertility appear negligible by comparison.

There were 2 exceptions to this pattern of a peak in the range 18 to 19 (Table 4). The hill tribes people of northern Thailand had a maximum attractiveness at BMI $=25.6$ (Swami \& Tovée 2007), and the Zulus of South Africa had a maximum attractiveness at BMI = 28.9. In these latter cases the maximum clearly sits much closer to the predictions of the evolutionary model derived here. Although insufficient images and data were available to fit an exact curve it seems likely that similar data with higher BMIs at maximal levels of attractiveness would also be observed among the Hadza of Tanzania (Marlowe \& Wetsman 2001).One hypothesis is that these divergent patterns emerge because these communities do not use BMI as a proxy for age, and the resultant pattern then matches more closely the evolutionary predictions from the model excluding such a link. This may be because in these communities, that are all resource poor, body fatness does not increase with age in the same way it does in modern societies (Lawrence et al. 1987; Prentice et al. 1981), and hence low BMI is not an honest signal of youthfulness. 
Conclusions

631 Our data confirm previous studies showing body fatness (and BMI) explained more of the variation in ratings of physical attractiveness than waist to hip ratio (WHR). Novel here was the demonstration that WHR played a more important role (greater $\mathrm{r}^{2}$ ) in African than in Asian populations. The relationships between attractiveness and body fatness (BMI) did not match the predictions from a theoretical model based on large epidemiological studies of the impacts of body fatness on health and fertility, combined with the relationship between fatness and famine survival. An explanation for this discrepancy is that raters used the body fatness of the subject images as a proxy for subject age, and age is more strongly linked to fertility than is BMI (independent of age). A model based on this assumption matched our, and previous, data relating fatness to attractiveness. Overall our data and modeling suggest that the role of BMI in ratings of attractiveness may have been overstated because of the covariance of BMI with age. Future studies aiming to quantify the contribution of body fatness (BMI or BF \%) and WHR to ratings of physical attractiveness need to remove any covariance between fatness (BMI or BF\%), WHR and age.

\section{Author Contributions:}

Guanlin Wang recruited participants and did the investigation in China and analyzed the data of all the countries and co-wrote the manuscript; Mark

D. Faries provided the DXA images and advice on the study protocol; Chima A. Egedigwe did the investigation in Nigeria; Kurosh Djafarian did the investigation in Iran, Robert Ojiambo did the investigation in Kenya, Harris 
Ramuth did the work in Mauritius; El Hamdouchi Asmaa did the project in Morocco, and Lobke

Vaanholt, Justina Sauciuvenaite and Catherine Hambly did the work in the UK, Justina

Sauciuvenaite did the study in Lithuania, Sandra Johanna Wallner-Liebmann and Sonja Lackner

did the work in Austria, Adama Diouf did the work in Senegal, John R. Speakman designed the

study, built the evolutionary model and co-wrote the manuscript. All authors contributed to and

approved the manuscript for submission.

657

658

659

\section{Acknowledgements}

We are grateful to all the participants from all the countries and all the members of Molecular

Energetics Group for their help on the investigation and discussion of the results.

\section{References}

Andersson M, and Simmons LW. 2006. Sexual selection and mate choice. Trends Ecol Evol 21:296-302.

Bigaard J, Frederiksen K, Tjonneland A, Thomsen BL, Overvad K, Heitmann BL, and Sorensen TI. 2004. Body fat and fat-free mass and all-cause mortality. Obes Res 12:1042-1049.

Borgerhoff Mulder M. 1998. Reproductive success in three Kipsigis cohorts. Reproductive success:419-435. Hislop TG. 2003. Waist-to-hip ratio and breast cancer mortality. Am J Epidemiol 158:963-968.

Chan JM, Rimm EB, Colditz GA, Stampfer MJ, and Willett WC. 1994. Obesity, fat distribution, and weight gain as risk factors for clinical diabetes in men. Diabetes care 17:961-969.

Cohen SS, Park Y, Signorello LB, Patel AV, Boggs DA, Kolonel LN, Kitahara CM, Knutsen SF, Gillanders E, and Monroe KR. 2014. A Pooled Analysis of Body Mass Index and Mortality among African Americans. PLoS One 9:e111980.

Cohen SS, Signorello LB, Cope EL, McLaughlin JK, Hargreaves MK, Zheng W, and Blot WJ. 2012. Obesity and allcause mortality among black adults and white adults. American Journal of Epidemiology 176:431-442. 
Crossley KL, Cornelissen PL, and Tovee MJ. 2012. What is an attractive body? Using an interactive 3D program to create the ideal body for you and your partner. PLoS One 7:e50601.

Cunningham MR, Roberts AR, Barbee AP, Druen PB, and Wu CH. 1995. "Their ideas of beauty are, on the whole, the same as ours": Consistency and variability in the cross-cultural perception of female physical attractiveness. J Pers Soc Psychol 68:261-279.

Despres JP. 2012. Body fat distribution and risk of cardiovascular disease: an update. Circulation 126:1301-1313.

Dixson BJ, Dixson AF, Li B, and Anderson MJ. 2007. Studies of human physique and sexual attractiveness: sexual preferences of men and women in China. Am J Hum Biol 19:88-95.

Drury NE. 2000. Beauty is only skin deep. J R Soc Med 93:89-92.

Eagly AH, Ashmore RD, Makhijani MG, and Longo LC. 1991. What is beautiful is good, but...:A meta-analytic review of research on the physical attractiveness stereotypePsychological bulletin, 110 1, 109. Psycological bulletin 110:109-128.

Eknoyan G. 2001. The importance of early treatment of the anaemia of chronic kidney disease. Nephrol Dial Transplant 16 Suppl 5:45-49.

Fallon AE, and Rozin P. 1985. Sex differences in perceptions of desirable body shape. J Abnorm Psychol 94:102-105. Faries MD, and Bartholomew JB. 2012. The role of body fat in female attractiveness. Evol Hum Behav 33:672-681.

Flegal KM, Kit BK, Orpana H, and Graubard BI. 2013. Association of all-cause mortality with overweight and obesity using standard body mass index categories: a systematic review and meta-analysis. JAMA 309:71-82.

Freedman DS, Kahn HS, Mei Z, Grummer-Strawn LM, Dietz WH, Srinivasan SR, and Berenson GS. 2007. Relation of body mass index and waist-to-height ratio to cardiovascular disease risk factors in children and adolescents: the Bogalusa Heart Study. Am J Clin Nutr 86:33-40.

Freedman RE, Carter MM, Sbrocco T, and Gray JJ. 2004. Ethnic differences in preferences for female weight and waist-to-hip ratio: a comparison of African-American and White American college and community samples. Eat Behav 5:191-198.

Furnham A, Dias M, and McClelland A. 1998. The role of body weight, waist-to-hip ratio, and breast size in judgments of female attractiveness. Sex Roles 39:311-326.

Furnham A, Moutafi J, and Baguma P. 2002. A cross-cultural study on the role of weight and waist-to-hip ratio on female attractiveness, 32, 729-745. Person Individ Diff 32:729-745.

Furnham A, Tan T, and McManus C. 1997. Waist-to-hip ratio and preferences for body shape: A replication and extension. Person Individ Diff 22:539-549.

Grammer K, and Thornhill R. 1994. Human (Homo sapiens) facial attractiveness and sexual selection: the role of symmetry and averageness. J Comp Psychol 108:233-242.

Groesz LM, Levine MP, and Murnen SK. 2002. The effect of experimental presentation of thin media images on body satisfaction: A meta - analytic review. International Journal of Eating Disorders 31:1-16.

Hall KD. 2012. Quantitative physiology of human starvation: Adaptations of energy expenditure, macronutrient metabolism and body composition. Comparative Physiology of Fasting, Starvation, and Food Limitation: Springer, 379-393.

Henry L. 1961. Some data on natural fertility. Biodemography and Social Biology 8:81-91.

Henss R. 1995. Waist-to-hip ratio and attractiveness. Replication and extension. Person Individ Diff 19:479-488.

Henss R. 2000. Waist-to-hip ratio and female attractiveness. Evidence from photographic stimuli and methodological considerations. Person Individ Diff 28:501-513. 
Jacobsen BK, Knutsen SF, Oda K, and Fraser GE. 2013. Body mass index at age 20 and subsequent childbearing: The Adventist Health Study-2. Journal of Women's Health 22:460-466.

Katzmarzyk PT, and Davis C. 2001. Thinness and body shape of Playboy centerfolds from 1978 to 1998. Int J Obes Relat Metab Disord 25:590-592.

Kościński K. 2012. Mere visual experience impacts preference for body shape: evidence from male competitive swimmers. Evolution and Human Behavior 33:137-146.

Kościński K. 2013. Attractiveness of women's body: body mass index, waist-hip ratio, and their relative importance. Behavioral Ecology 24:914-925.

Kościński K. 2014. Assessment of waist-to-hip ratio attractiveness in women: An anthropometric analysis of digital silhouettes. Archives of Sexual Behavior 43:989-997.

Lawrence M, Lawrence F, Coward WA, Cole TJ, and Whitehead RG. 1987. Energy requirements of pregnancy in The Gambia. Lancet 2:1072-1076.

Leridon H. 1978. Fertility and demographic structures: a hypothesis on fertility change since 1940. Population 33:441-447.

Leridon H. 2008. A new estimate of permanent sterility by age: sterility defined as the inability to conceive. Popul Stud (Camb) 62:15-24.

Lev-Ran A. 2001. Human obesity: an evolutionary approach to understanding our bulging waistline. Diabetes Metab Res Rev 17:347-362.

Marlowe F, Apicella C, and Reed D. 2005. Men's preferences for women's profile waist-to-hip ratio in two societies. Evol Hum Behav 26:458-468.

Marlowe F, and Wetsman A. 2001. Preferred waist-to-hip ratio and ecology. Person Individ Diff 30:481-489.

Menken J, and Larsen U. 1986. Fertility rates and aging. Aging, reproduction, and the climacteric: Springer, 147166.

Mo JJ, Cheung KW, Gledhill L, Pollet TV, Boothroyd LG, and Tovée MJ. 2014. Perceptions of Female Body Size and Shape in China, Hong Kong, and the United Kingdom. Cross-Cultural Research 48:78-103.

Neel JV. 1962. Diabetes mellitus: a "thrifty" genotype rendered detrimental by "progress"? Am J Hum Genet 14:353-362.

Pawlowski B, and Sorokowski P. 2008. Men's attraction to women's bodies changes seasonally. Perception 37:1079-1085.

Perrett DI, Lee KJ, Penton-Voak I, Rowland D, Yoshikawa S, Burt DM, Henzi SP, Castles DL, and Akamatsu S. 1998. Effects of sexual dimorphism on facial attractiveness. Nature 394:884-887.

Pittenger DB. 1973. An exponential model of female sterility. Demography 10:113-121.

Posavac HD, Posavac SS, and Posavac EJ. 1998. Exposure to Media Images of Female Attractiveness and Concern with Body Weight Among Young Women1. Sex Roles 38:187-201.

Prentice AM, Whitehead RG, Roberts SB, and Paul AA. 1981. Long-term energy balance in child-bearing Gambian women. Am J Clin Nutr 34:2790-2799.

Price ME, Pound N, Dunn J, Hopkins S, and Kang J. 2013. Body shape preferences: associations with rater body shape and sociosexuality. PLoS One 8:e52532.

Roberts III TL, Weinfeld AB, Bruner TW, and Nguyen K. 2006. "Universal" and ethnic ideals of beautiful buttocks are best obtained by autologous micro fat grafting and liposuction. Clin Plast Surg 33:371.

Schmalt HD. 2006. Waist-to-hip ratio and female physical attractiveness: The moderating role of power motivation 
and the mating context. Person Individ Diff 41:455-465.

Singh D. 1993. Body shape and women's attractiveness : The critical role of waist-to-hip ratio. Hum Nat 4:297-321.

Singh D. 1994. Waist-to-hip ratio and judgment of attractiveness and healthiness of female figures by male and female physicians. Int J Obes Relat Metab Disord 18:731-737.

Singh D. 1995a. Female health, attractiveness, and desirability for relationships: Role of breast asymmetry and waist-to-hip ratio. , $16 \quad 6$, 465-481. Ethology and Sociobiology 16:465-481.

Singh D. 1995b. Female judgment of male attractiveness and desirability for relationships: role of waist-to-hip ratio and financial status. J Pers Soc Psychol 69:1089-1101.

Singh D, and Young RK. 1995. Body weight, waist-to-hip ratio, breasts, and hips: Role in judgments of female attractiveness and desirability for relationships. Ethology and Sociobiology 16:483-507.

Smith KL, Cornelissen PL, and Tovée MJ. 2007. Color 3D bodies and judgements of human female attractiveness. Evol Hum Behav 28:48-54.

Song B, and Thomas DM. 2007. Dynamics of starvation in humans. J Math Biol 54:27-43.

Speakman JR, and Goran MI. 2010. Tissue-specificity and ethnic diversity in obesity-related risk of cancer may be explained by variability in insulin response and insulin signaling pathways. Obesity (Silver Spring) 18:10711078.

Speakman JR, and Westerterp KR. 2010. Associations between energy demands, physical activity, and body composition in adult humans between 18 and 96 y of age. Am J Clin Nutr 92:826-834.

Speakman JR, and Westerterp KR. 2013. A mathematical model of weight loss under total starvation: evidence against the thrifty-gene hypothesis. Dis Model Mech 6:236-251.

Streeter SA, and McBurney DH. 2003. Waist-hip ration and attractiveness: New evidence and a critique of "a critical test". Evol Hum Behav 24:88-98.

Swami V, Caprario C, Tovée MJ, and Furnham A. 2006a. Female physical attractiveness in Britain and Japan: A cross-cultural study. European Journal of Personality 20:69-81.

Swami V, Einon D, and Furnham A. 2006b. The leg-to-body ratio as a human aesthetic criterion. Body Image 3:317323.

Swami V, Frederick DA, Aavik T, Alcalay L, Allik J, Anderson D, Andrianto S, Arora A, Brannstrom A, Cunningham J, Danel D, Doroszewicz K, Forbes GB, Furnham A, Greven CU, Halberstadt J, Hao S, Haubner T, Hwang CS, Inman M, Jaafar JL, Johansson J, Jung J, Keser A, Kretzschmar U, Lachenicht L, Li NP, Locke K, Lonnqvist JE, Lopez C, Loutzenhiser L, Maisel NC, McCabe MP, McCreary DR, McKibbin WF, Mussap A, Neto F, Nowell C, Alampay LP, Pillai SK, Pokrajac-Bulian A, Proyer RT, Quintelier K, Ricciardelli LA, Rozmus-Wrzesinska M, Ruch W, Russo T, Schutz A, Shackelford TK, Shashidharan S, Simonetti F, Sinniah D, Swami M, Vandermassen G, van Duynslaeger M, Verkasalo M, Voracek M, Yee CK, Zhang EX, Zhang X, and ZivcicBecirevic I. 2010. The attractive female body weight and female body dissatisfaction in 26 countries across 10 world regions: results of the international body project I. Pers Soc Psychol Bull 36:309-325.

Swami V, and Tovée MJ. 2007. Differences in attractiveness preferences between observers in low-and highresource environments in Thailand. Journal of Evolutionary Psychology 5:149-160.

Swami V, and Tovee MJ. 2005. Female physical attractiveness in Britain and Malaysia: a cross-cultural study. Body Image 2:115-128.

Swami V, and Tovee MJ. 2006. Does hunger influence judgments of female physical attractiveness? Br J Psychol 97:353-363. 
Swami V, and Tovee MJ. 2012. The impact of psychological stress on men's judgements of female body size. PLoS One 7:e42593.

Tassinary LG, and Hansen KA. 1998. A critical test of the waist-to-hip-ratio hypothesis of female physical attractiveness. Psychological Science 9:150-155.

Terry RB, Page WF, and Haskell WL. 1992. Waist/hip ratio, body mass index and premature cardiovascular disease mortality in US Army veterans during a twenty-three year follow-up study. Int J Obes Relat Metab Disord 16:417-423.

Thornhill R, Gangestad SW, Miller R, Scheyd G, McCollough JK, and Franklin M. 2003. Major histocompatibility complex genes, symmetry, and body scent attractiveness in men and women. Behavioral Ecology 14:668678.

Tovée MJ, Swami V, Furnham A, and Mangalparsad R. 2006. Changing perceptions of attractiveness as observers are exposed to a different culture. Evol Hum Behav 26:458-468.

Tovee MJ, Brown JE, and Jacobs D. 2001. Maternal waist-to-hip ratio does not predict child gender. Proc Biol Sci 268:1007-1010.

Tovee MJ, and Cornelissen PL. 1999. The mystery of female beauty. Nature 399:215-216.

Tovee MJ, and Cornelissen PL. 2001. Female and male perceptions of female physical attractiveness in front-view and profile. Br J Psychol 92 Part 2:391-402.

Tovee MJ, Hancock PJ, Mahmoodi S, Singleton BR, and Cornelissen PL. 2002. Human female attractiveness: waveform analysis of body shape. Proc Biol Sci 269:2205-2213.

Tovee MJ, Maisey DS, Emery JL, and Cornelissen PL. 1999. Visual cues to female physical attractiveness. Proc Biol Sci 266:211-218.

Tovee MJ, Mason SM, Emery JL, McCluskey SE, and Cohen-Tovee EM. 1997. Supermodels: stick insects or hourglasses? Lancet 350:1474-1475.

Tovee MJ, Reinhardt S, Emery JL, and Cornelissen PL. 1998. Optimum body-mass index and maximum sexual attractiveness. Lancet 352:548.

Trivers R. 1985. Social evolution: Menlo Park, CA: Benjamin/Cummings.

Trussell J, and Wilson C. 1985. Sterility in a population with natural fertility. Population Studies 39:269-286.

Vincent P. 1950. La stérilité physiologique des populations. Population (french edition):45-64.

Voracek M, and Fisher ML. 2002. Shapely centrefolds? Temporal change in body measures: trend analysis. BMJ 325:1447-1448.

Wallace WH, and Kelsey TW. 2010. Human ovarian reserve from conception to the menopause. PLoS One 5:e8772. Wass $P$, Waldenstrom U, Rossner S, and Hellberg D. 1997. An android body fat distribution in females impairs the pregnancy rate of in-vitro fertilization-embryo transfer. Hum Reprod 12:2057-2060.

Whitlock G, Lewington S, Sherliker P, Clarke R, Emberson J, Halsey J, Qizilbash N, Collins R, and Peto R. 2009. Bodymass index and cause-specific mortality in 900000 adults: collaborative analyses of 57 prospective studies. Lancet 373:1083-1096.

Zheng W, McLerran DF, Rolland B, Zhang X, Inoue M, Matsuo K, He J, Gupta PC, Ramadas K, and Tsugane S. 2011. Association between body-mass index and risk of death in more than 1 million Asians. New England Journal of Medicine 364:719-729. 


\section{Figure Legends}

Fig.1 A. Epidemiological data linking all cause mortality to body fatness (BMI) for female subjects minus the mortality for the class with the lowest mortality (data from Whitlock et al 2009 for Caucasians; Zheng et al 2011 for Asians and Cohen et al 2012, 2014 for African Americans). The curves are the fitted third order polynomials (see text for details)B. probability of nulliparity over entire reproductive age annualized per 1000 population (open symbols) and probability of not having a second child if one child has already been born annualized per 1000 population (closed symbols) as a function of BMI at age 20. Data are subtracted from the class with the lowest probabilities (data from Jacobsen et al 2014).. C. Combined effects of infertility and all cause mortality in relation to BMI (effective mortality risk per 1000 population) for each ethnic group. The minimum point of the curve is at BMI = 23.18 for Caucasians, 23.12 for Asians and 22.45 for African Americans (see text for derivation details). D. Combined effects of infertility and all cause mortality (as in c) as well as the impact of fatness on famine survival on the relationship between mortality and Body mass index (effective mortality per 1000 population). The minimum points of the curves are at BMI $=24.78$ for Caucasians, 24.72 for Asians and 24.05 for African Americans (see text for derivation details).

Fig. 2 Relationship between the rankings by males and females of the attractiveness of 21 DXA soft tissue images of females, of varying BMI and waist to hip ratio, across 9 populations(except 
862 Senegal). The $\mathrm{X}$-axis is the rating by females and the $\mathrm{Y}$-axis the rating by the males

863 Fig. 3 Relationships between the average ratings of physical attractiveness of 21 DXA soft tissue

864 images and body fat $\%$ of the subjects in the images across ten different populations. (error bar

865 referred to the standard error of both directions)

866 Fig. 4 Relationships between the average ratings of physical attractiveness of 21 DXA soft tissue

867 images and waist to hip ratios (WHR) of the subjects in the images across ten different

868 populations. (error bar referred to the standard error of both directions)

869 Fig. 5 Relationships between estimated subject age and A) actual subject age, B) subject body

870 fatness, C) subject BMI, D) subject WHR for 21 DXA soft tissue images averaged across 325

871 mixed sex raters in six different countries. 


\section{Table $\mathbf{1}$ (on next page)}

Table 1. Details of the rating participants from each country

*one missing gender in Nigeria population 
Table 1. Details of the rating participants from each country

\begin{tabular}{|c|c|c|c|c|c|c|c|c|c|}
\hline Country & $\mathbf{N}$ & Female & Male & All & Female & Male & All & Female & Male \\
\hline Austria & 53 & 45 & 8 & $27.5 \pm 9.8$ & $26.8 \pm 8.8$ & $31.5 \pm 14.2$ & $24.0 \pm 5.9$ & $23.8 \pm 6.1$ & $24.9 \pm 4.3$ \\
\hline UK & 85 & 48 & 37 & $23.2 \pm 6.1$ & $24.1 \pm 7.1$ & $22.0 \pm 4.3$ & $23.1 \pm 3.7$ & $22.6 \pm 3.9$ & $23.6 \pm 3.5$ \\
\hline Lithuania & 60 & 41 & 19 & $34.1 \pm 11.9$ & $36.6 \pm 12.1$ & $28.7 \pm 9.8$ & $23.9 \pm 3.9$ & $24.1 \pm 4.1$ & $23.5 \pm 3.7$ \\
\hline China & 209 & 98 & 111 & $25.4 \pm 5.3$ & $25.7 \pm 6.1$ & $25.2 \pm 4.5$ & $21.5 \pm 2.5$ & $20.5 \pm 2.2$ & $22.3 \pm 2.6$ \\
\hline Iran & 180 & 115 & 65 & $30.2 \pm 10.6$ & $31.0 \pm 10.4$ & $28.8 \pm 10.9$ & $26.8 \pm 6.3$ & $27.0 \pm 5.8$ & $26.4 \pm 7.2$ \\
\hline Kenya & 104 & 43 & 61 & $22.3 \pm 4.1$ & $21.0 \pm 1.7$ & $23.2 \pm 5.0$ & $21.8 \pm 2.9$ & $22.3 \pm 2.8$ & $21.4 \pm 2.9$ \\
\hline Morocco & 260 & 132 & 128 & $24.1 \pm 4.8$ & $23.5 \pm 3.9$ & $24.7 \pm 5.5$ & $22.9 \pm 3.0$ & $22.5 \pm 3.2$ & $23.3 \pm 2.8$ \\
\hline Senegal & 135 & 135 & 0 & $25.3 \pm 3.9$ & $25.3 \pm 3.9$ & - & $22.7 \pm 5.8$ & $22.7 \pm 5.8$ & - \\
\hline Total* & 1327 & 817 & 509 & & & & & & \\
\hline
\end{tabular}

1 *one missing gender in Nigeria population 
Table 2 (on next page)

Univariate analyses

Parameters of least squares fit regression equations relating BF\%, BMI and WHR to average attractiveness across 21 DXA soft tissue images. In all cases the df for the F statistic was 1,19 . 
1 Table 2. Univariate analyses. Parameters of least squares fit regression equations relating $\mathrm{BF} \%$,

2 BMI and WHR to average attractiveness across 21 DXA soft tissue images. In all cases the $\mathrm{df}$ for

3 the F statistic was 1,19 .

4 A. $\mathrm{BF} \%$

\begin{tabular}{lcccc}
\hline \multicolumn{1}{c}{ Country } & Equation & R square & $F$ & P-value \\
\hline Austria & $\mathrm{y}=-0.1995 \mathrm{x}+11.784$ & 0.853 & 110.41 & $<0.001$ \\
Lithuania & $\mathrm{y}=-0.185 \mathrm{x}+11.301$ & 0.769 & 63.18 & $<0.001$ \\
UK & $\mathrm{y}=-0.187 \mathrm{x}+11.368$ & 0.758 & 59.55 & $<0.001$ \\
China & $\mathrm{y}=-0.199 \mathrm{x}+11.779$ & 0.828 & 91.48 & $<0.001$ \\
Iran & $\mathrm{y}=-0.201 \mathrm{x}+11.831$ & 0.853 & 110.07 & $<0.001$ \\
Mauritius & $\mathrm{y}=-0.183 \mathrm{x}+11.222$ & 0.839 & 99.18 & $<0.001$ \\
Kenya & $\mathrm{y}=-0.185 \mathrm{x}+11.289$ & 0.751 & 57.3 & $<0.001$ \\
Morocco & $\mathrm{y}=-0.143 \mathrm{x}+9.868$ & 0.641 & 33.92 & $<0.001$ \\
Nigeria & $\mathrm{y}=-0.113 \mathrm{x}+8.850$ & 0.463 & 16.37 & $<0.001$ \\
Senegal & $\mathrm{y}=-0.103 \mathrm{x}+8.504$ & 0.596 & 27.99 & $<0.001$ \\
\hline
\end{tabular}

5

6 B. BMI

\begin{tabular}{lcccc}
\hline \multicolumn{1}{c}{ Country } & Equation & R square & $F$ & P-value \\
\hline Austria & $\mathrm{y}=-0.3833+14.766$ & 0.767 & 62.39 & $<0.001$ \\
Lithuania & $\mathrm{y}=-0.369 \mathrm{x}+14.397$ & 0.741 & 54.51 & $<0.001$
\end{tabular}




\begin{tabular}{llccc} 
UK & $y=-0.376 x+14.574$ & 0.743 & 54.94 & $<0.001$ \\
China & $y=-0.39 x+14.941$ & 0.772 & 64.36 & $<0.001$ \\
Iran & $y=-0.394 x+15.03$ & 0.797 & 74.66 & $<0.001$ \\
Mauritius & $y=-0.360 x+14.164$ & 0.789 & 71.19 & $<0.001$ \\
Kenya & $y=-0.376 x+14.586$ & 0.756 & 59.04 & $<0.001$ \\
Morocco & $y=-0.301 x+12.67$ & 0.69 & 42.29 & $<0.001$ \\
Nigeria & $y=-0.279 x+12.095$ & 0.682 & 40.66 & $<0.001$ \\
Senegal & $y=-0.232 x+10.897$ & 0.732 & 51.80 & $<0.001$ \\
\hline
\end{tabular}

8 C. WHR

\begin{tabular}{lcccc}
\hline \multicolumn{1}{c}{ Country } & Equation & R square & F & P-value \\
\hline Austria & $\mathrm{y}=-9.882 \mathrm{x}+12.181$ & 0.128 & 2.79 & $>0.05$ \\
Lithuania & $\mathrm{y}=-11.152 \mathrm{x}+13.103$ & 0.170 & 3.90 & $>0.05$ \\
UK & $\mathrm{y}=-12.866 \mathrm{x}+14.349$ & 0.219 & 5.32 & $<0.05$ \\
China & $\mathrm{y}=-10 \mathrm{x}+12.271$ & 0.128 & 2.78 & $>0.05$ \\
Iran & $\mathrm{y}=-9.15 \mathrm{x}+11.65$ & 0.108 & 2.31 & $>0.05$ \\
Mauritius & $\mathrm{y}=-7.09 \mathrm{x}+10.153$ & 0.077 & 1.59 & $>0.05$ \\
Kenya & $\mathrm{y}=-13.66 \mathrm{x}+14.927$ & 0.251 & 6.35 & $<0.05$ \\
Morocco & $\mathrm{y}=-12.14 \mathrm{x}+13.823$ & 0.282 & 7.46 & $<0.05$ \\
Nigeria & $\mathrm{y}=-12.02 \mathrm{x}+13.731$ & 0.319 & 8.89 & $<0.01$
\end{tabular}




Senegal $\quad y=-9.007+11.545 \quad 0.278 \quad 7 \quad<0.05$

9

10

11 


\section{Table 3 (on next page)}

Multiple regression analyses

Effects of subject body fatness (BF\%), waist to hip ratio (WHR) and age on average attractiveness using general linear models run separately for each of seven separate populations. Parameters of the full models and regression coefficients are in supplementary Table S2. df for all F statistics are 1,17 
1 Table 3. Multiple regression analyses: Effects of subject body fatness (BF\%), waist to hip ratio

2 (WHR) and age on average attractiveness using general linear models run separately for each of

3 seven separate populations. Parameters of the full models and regression coefficients are in

4 supplementary Table S2. df for all F statistics are 1,17

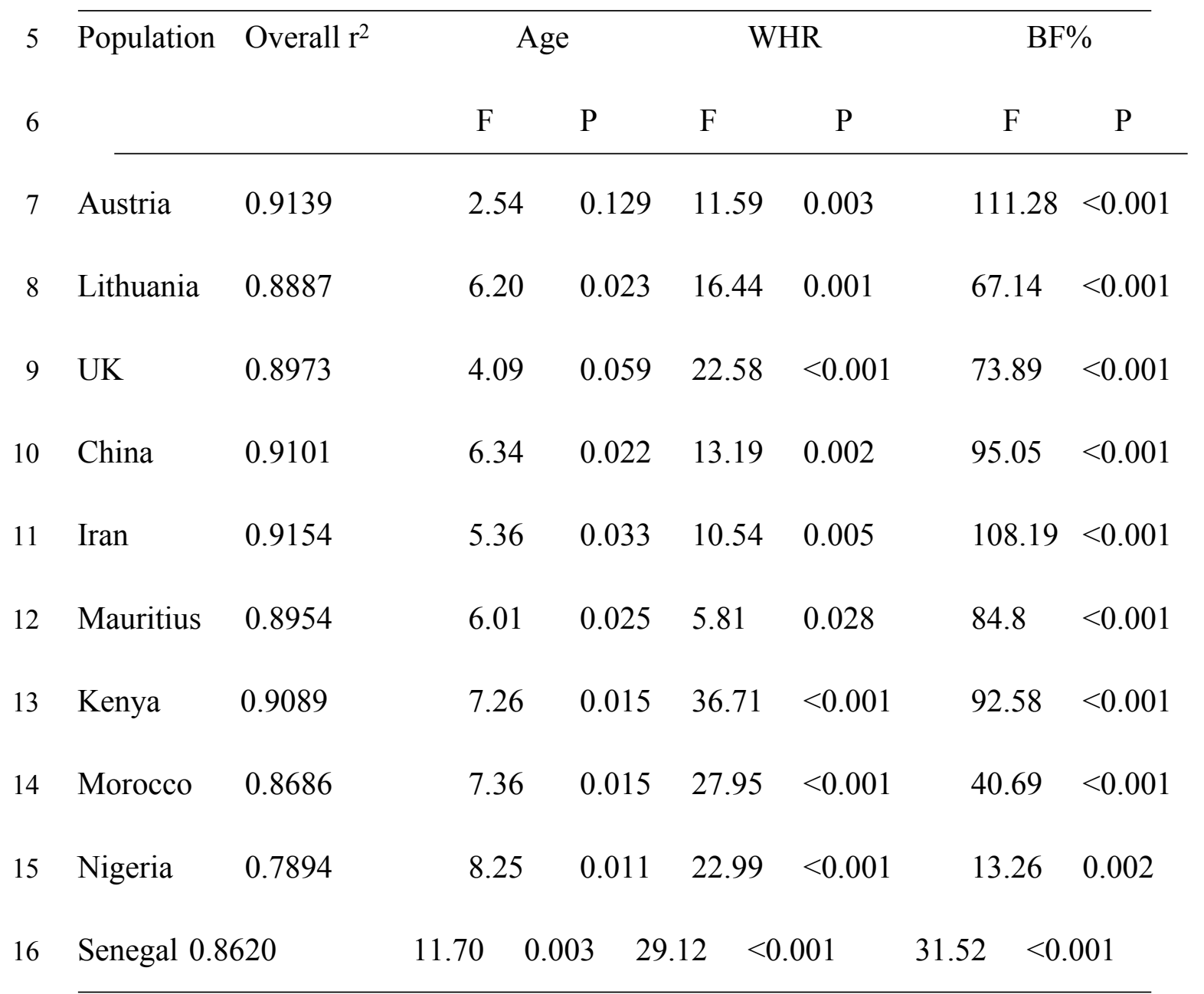




\section{Table 4(on next page)}

Table 4: Parameters of 3rd order polynomials fitted to data on attractiveness as a function of BMI in previous studies

Table 4: Parameters of 3rd order polynomials fitted to data on attractiveness as a function of BMI in previous studies in the literature, along with the estimated BMI at 'peak' attractiveness obtained by differentiating the fitted curves and solving the resultant quadratic equations for $f(x)=0$ in the range 3010 
1 Table 4: Parameters of 3rd order polynomials fitted to data on attractiveness as a function of

2 BMI in previous studies in the literature, along with the estimated BMI at 'peak' attractiveness

3 obtained by differentiating the fitted curves and solving the resultant quadratic equations for $\mathrm{f}(\mathrm{x})$

$4=0$ in the range $30<x>10$

\begin{tabular}{llllllll}
\hline 5 & Study & $\mathrm{x}^{3}$ & $\mathrm{x}^{2}$ & $\mathrm{x}$ & \multicolumn{1}{l}{ constant } & $\mathrm{r}^{2}$ & \multicolumn{1}{c}{ Peak } \\
\cline { 2 - 7 } 6 & 1 & 0.0019 & -0.1521 & 3.8397 & -26.003 & 0.732 & 20.486 \\
7 & $2 \mathrm{a}$ & 0.0016 & -0.1421 & 3.7809 & -26.817 & 0.842 & 20.185 \\
8 & $2 \mathrm{~b}$ & 0.0007 & -0.0651 & 2.0092 & -14.419 & 0.837 & 28.941 \\
9 & $3 \mathrm{a}$ & 0.0013 & -0.1053 & 2.5562 & -15.628 & 0.784 & 18.423 \\
10 & $3 \mathrm{~b}$ & 0.0016 & -0.1369 & 3.6632 & -26.131 & 0.830 & 21.431 \\
11 & $4 \mathrm{a}$ & 0.0023 & -0.1953 & 5.1321 & -36.786 & 0.826 & 20.731 \\
12 & $4 \mathrm{~b}$ & 0.0007 & -0.0654 & 1.973 & -12.878 & 0.800 & 25.633 \\
13 & $4 \mathrm{c}$ & 0.0021 & -0.1789 & 4.6963 & -33.44 & 0.768 & 20.591 \\
14 & 5 & 0.0018 & -0.1503 & 3.7823 & -25.23 & 0.725 & 19.215 \\
\hline
\end{tabular}

15 Studies were 1) Tovee et al 1999 2) Tovee et al 2010 a: British b: Zulus, 3) Swami et al 2010 a

16 Japanese b British 4) Swami et al a) British b) Hill tribe Thai c) city Thai.

17 5) Tovee et al 1998

18

19 


\title{
Figure 1 (on next page)
}

\author{
evolutionary model
}

A. Epidemiological data linking all cause mortality to body fatness (BMI) for female subjects minus the mortality for the class with the lowest mortality (data from Whitlock et al 2009 for Caucasians; Zheng et al 2011 for Asians and Cohen et al 2012, 2014 for African Americans). The curves are the fitted third order polynomials (see text for details) B. probability of nulliparity over entire reproductive age annualized per 1000 population (open symbols) and probability of not having a second child if one child has already been born annualized per 1000 population (closed symbols) as a function of BMI at age 20. Data are subtracted from the class with the lowest probabilities (data from Jacobsen et al 2014).. C. Combined effects of infertility and all cause mortality in relation to BMI (effective mortality risk per 1000 population) for each ethnic group. The minimum point of the curve is at $\mathrm{BMI}=23.18$ for Caucasians, 23.12 for Asians and 22.45 for African Americans (see text for derivation details).

D. Combined effects of infertility and all cause mortality (as in c) as well as the impact of fatness on famine survival on the relationship between mortality and Body mass index (effective mortality per 1000 population). The minimum points of the curves are at $\mathrm{BMI}=$ 24.78 for Caucasians, 24.72 for Asians and 24.05 for African Americans (see text for derivation details). 


\section{PeerJ Reviewing Manuscript}

\section{Figure 1}

A:

Annual excess mortality

Per 1000 population

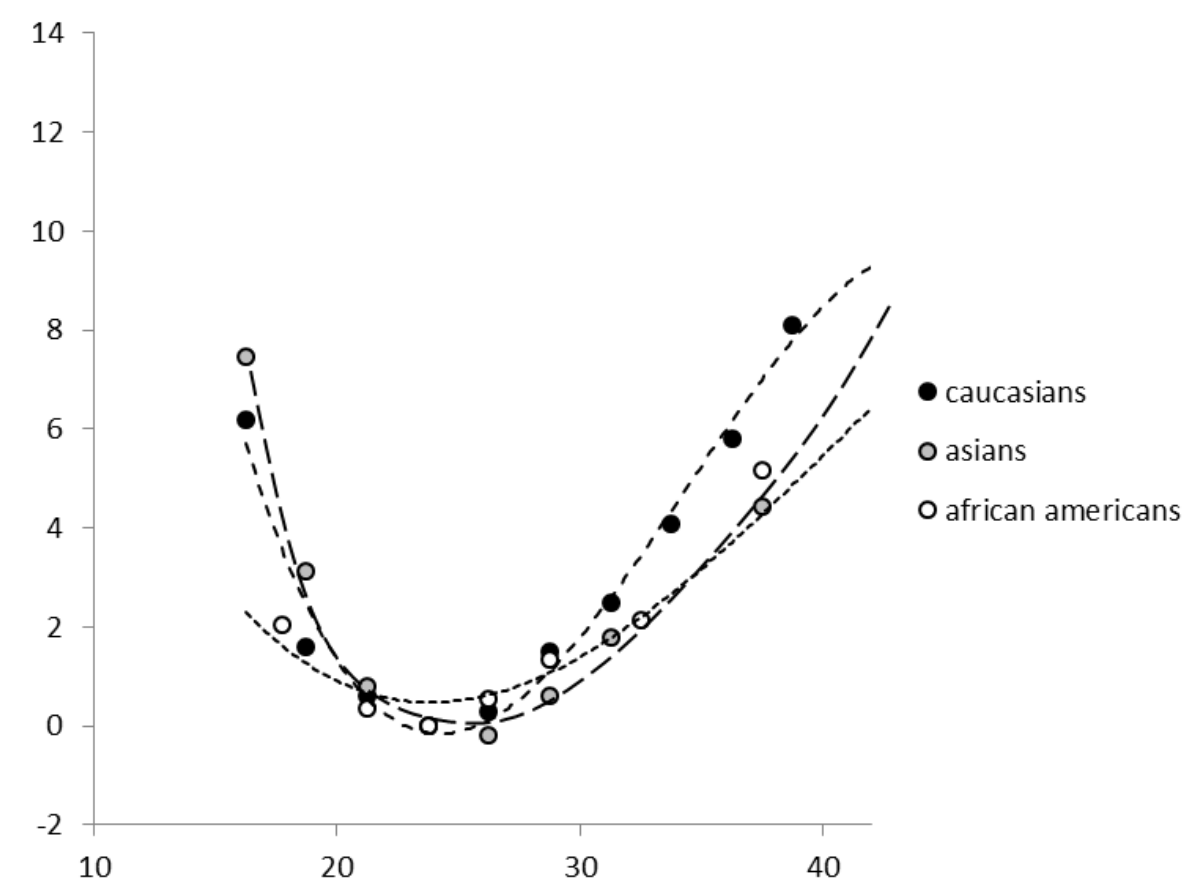

Body mass index

B:

Annual nulliparty and

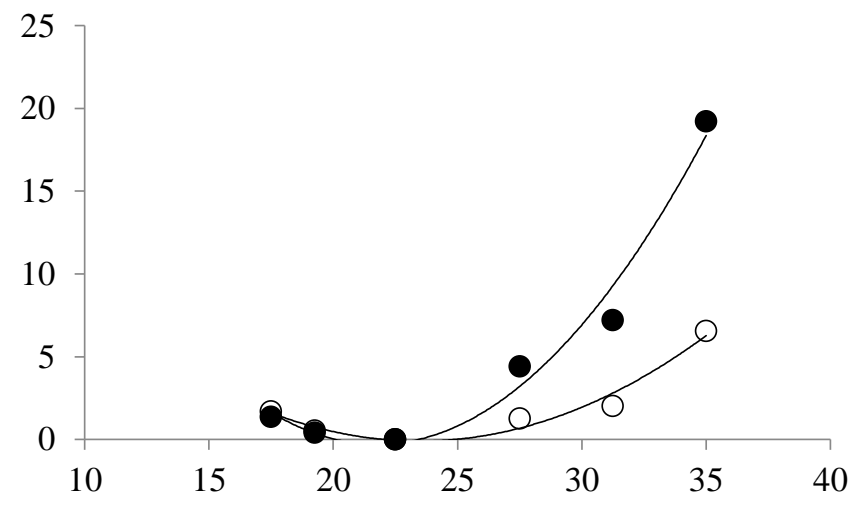

Body mass index 
C:

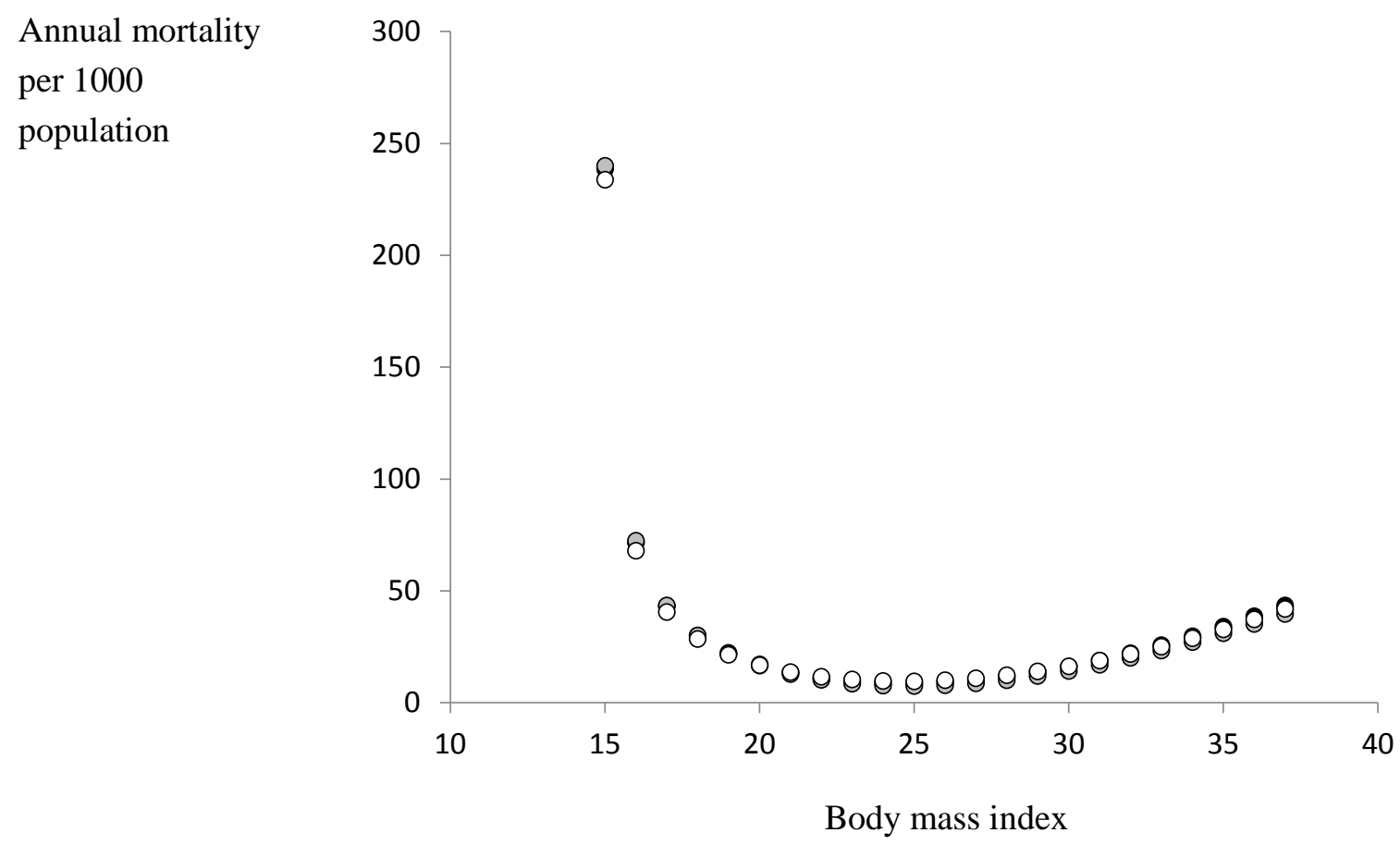

D:

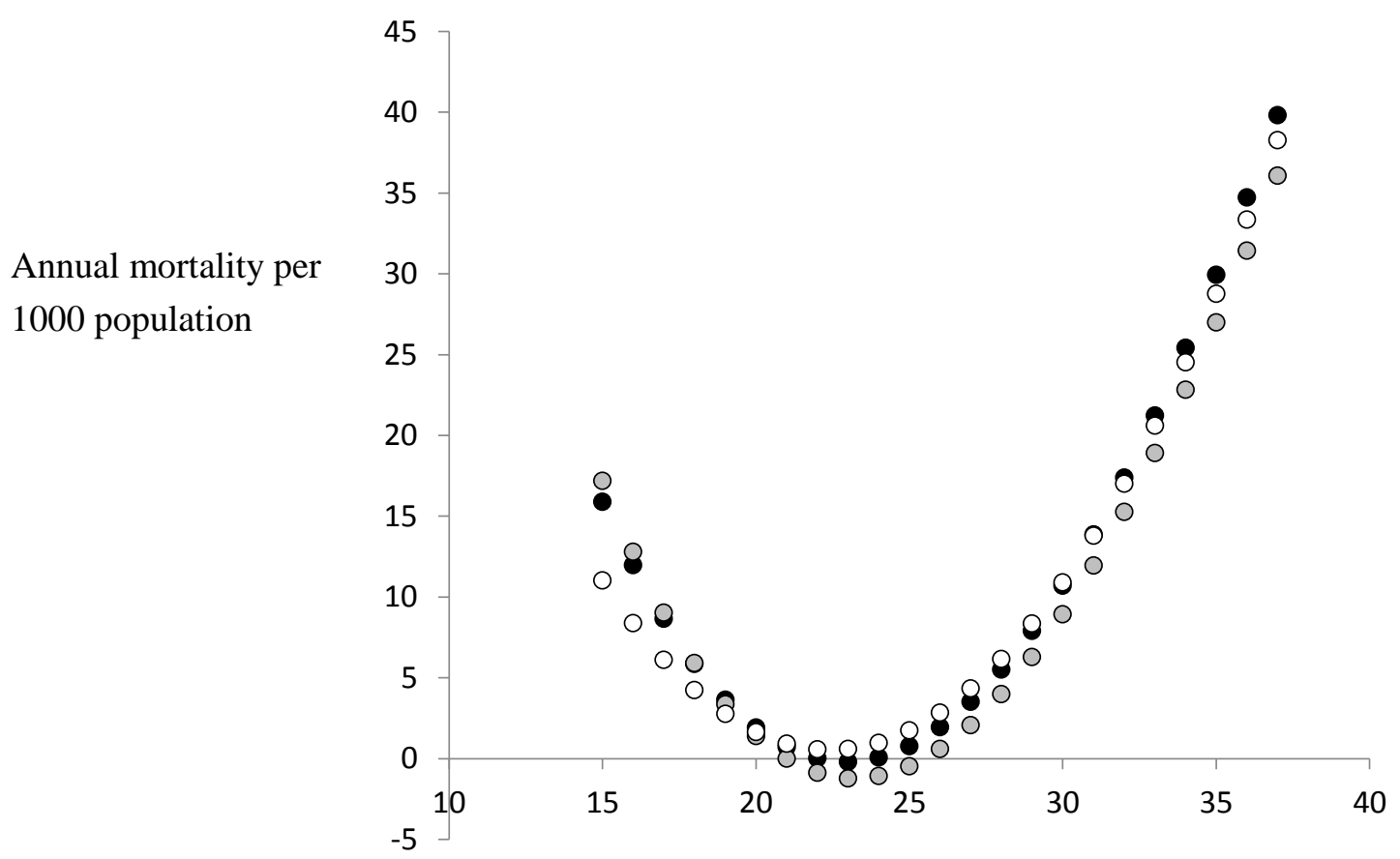

Body mass index 
Figure 2 (on next page)

Relationship between the rankings by males and females of the attractiveness of 21 DXA soft tissue images of females

Relationship between the rankings by males and females of the attractiveness of 21 DXA soft tissue images of females, of varying BMI and waist to hip ratio, across 9 populations(except Senegal). The $\mathrm{X}$-axis is the rating by females and the $\mathrm{Y}$-axis the rating by the males 

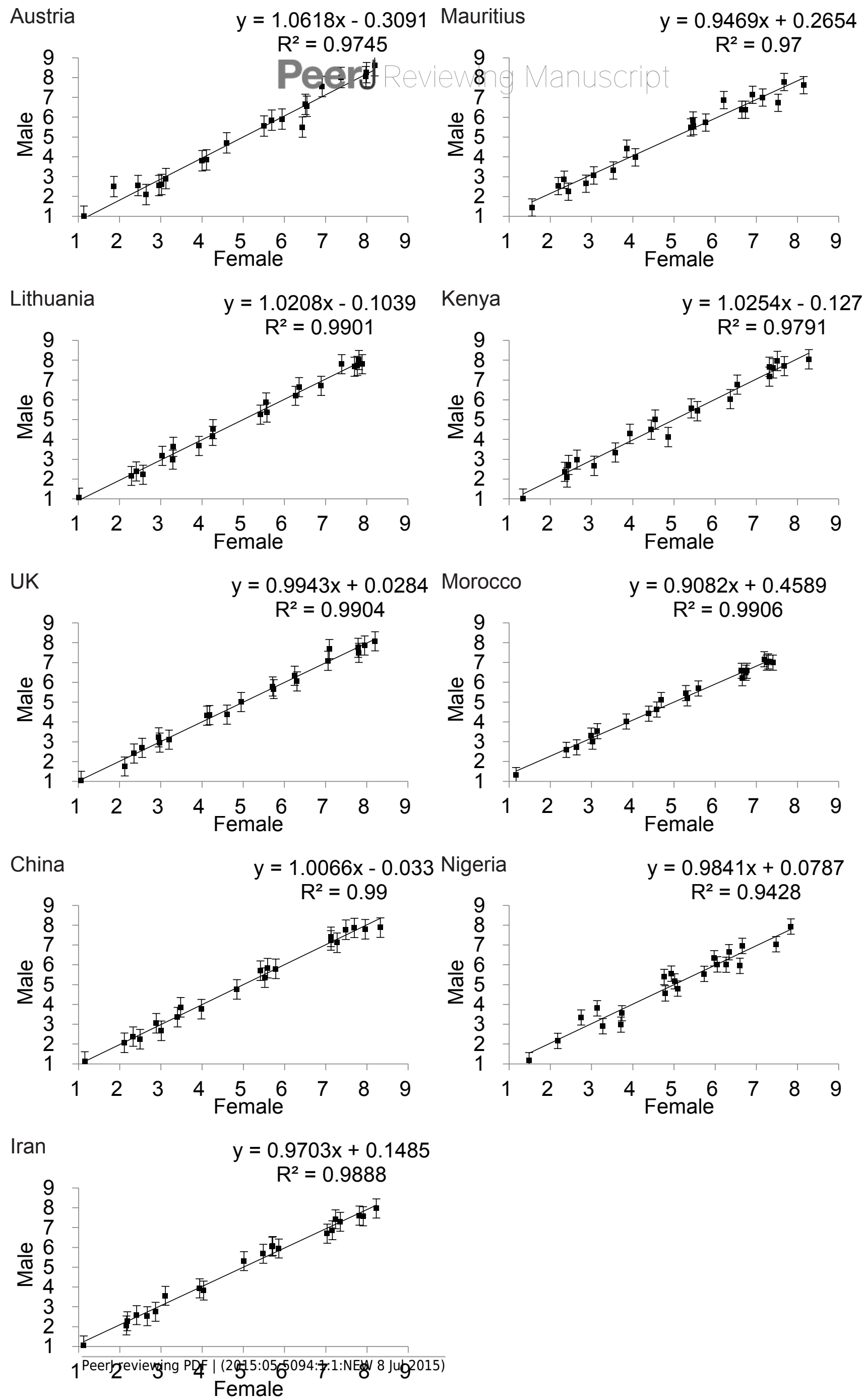
Figure 3 (on next page)

body fat percentage to attractiveness

Relationships between the average ratings of physical attractiveness of 21 DXA soft tissue images and body fat $\%$ of the subjects in the images across ten different populations. (error bar referred to the standard error of both directions) 
Austria $\quad y=-0.1995 x+11.784$ Mauritius $\quad y=-0.183 x+11.222$
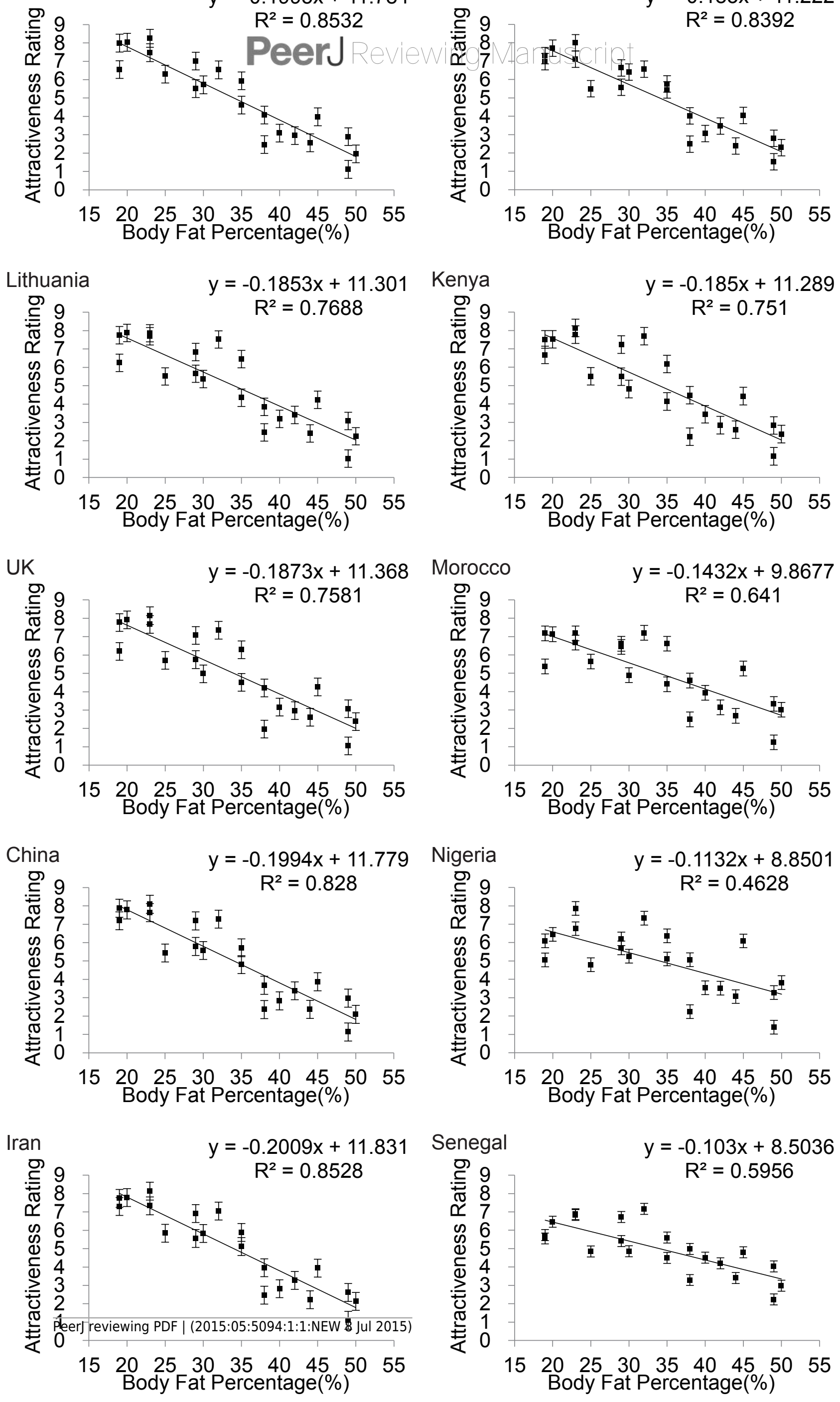
Figure 4 (on next page)

Relationships between the average ratings of physical attractiveness of 21 DXA soft tissue images and waist to hip ratios (WHR) of the subjects in the images across ten different populations.

Relationships between the average ratings of physical attractiveness of 21 DXA soft tissue images and waist to hip ratios (WHR) of the subjects in the images across ten different populations. (error bar referred to the standard error of both directions) 


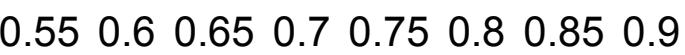
Waist-to-Hip Ratio(WHR)
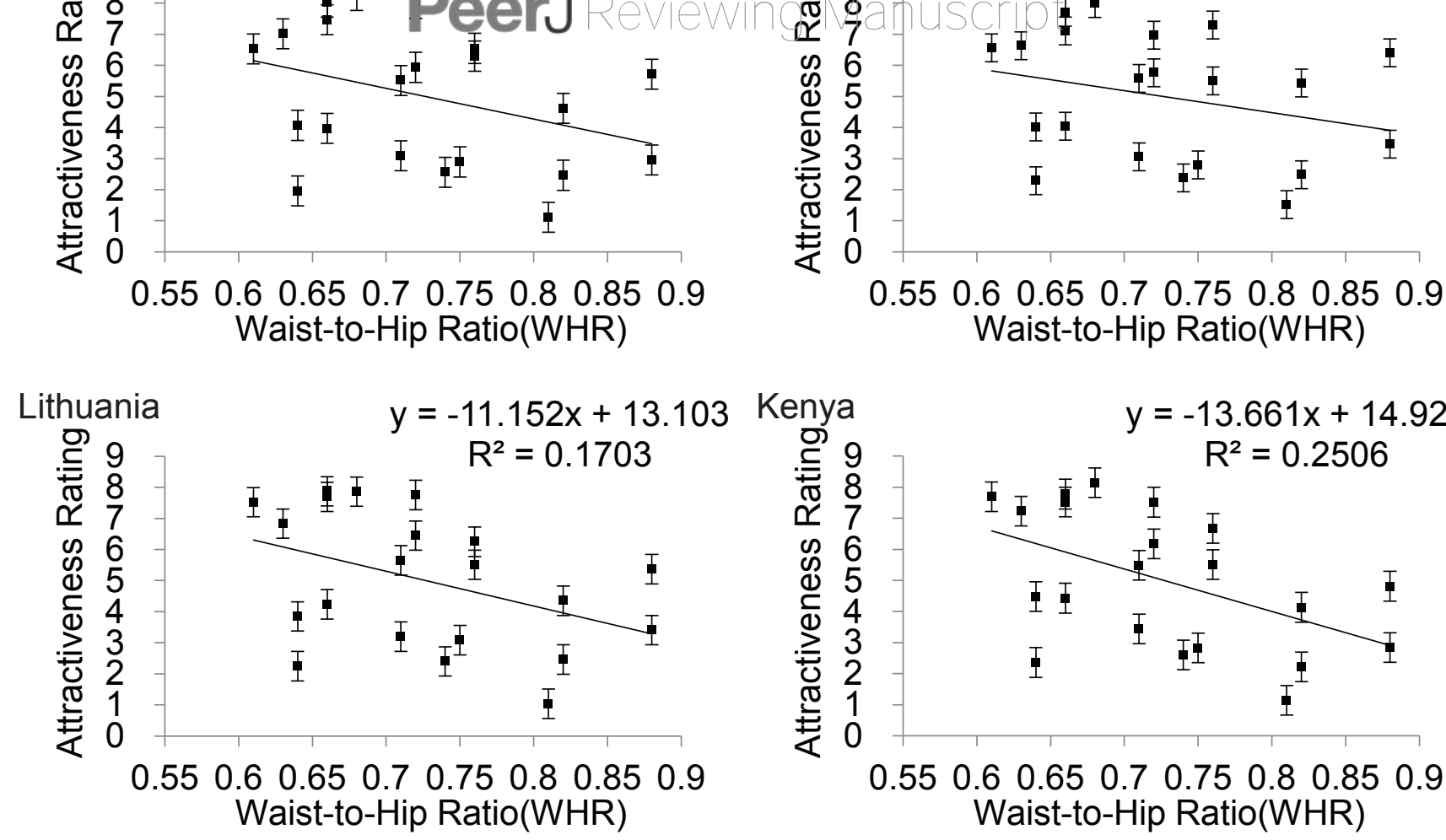

UK
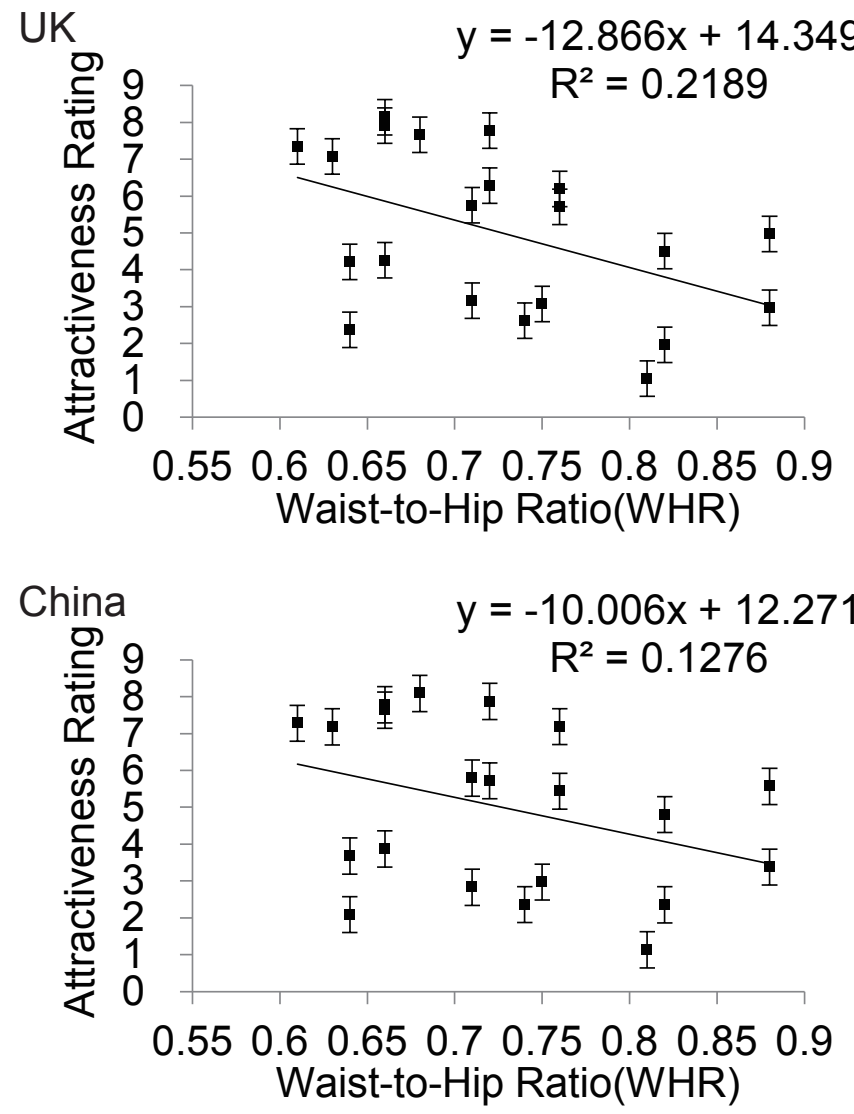

Iran

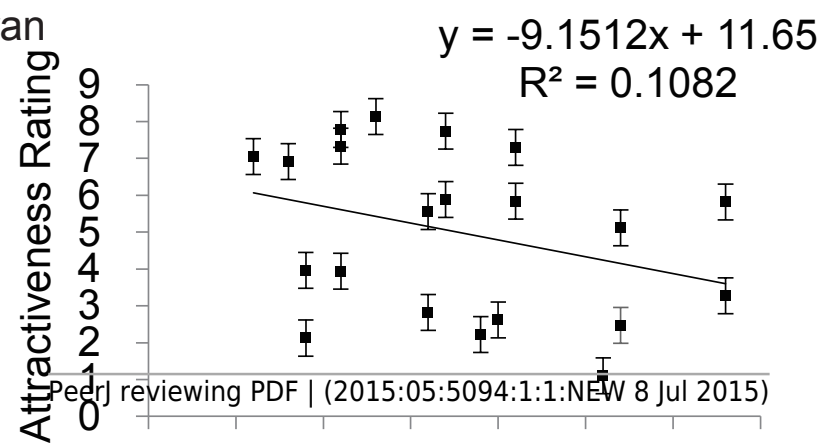

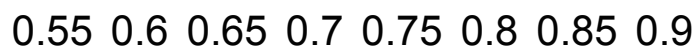
Waist-to-Hip Ratio(WHR)

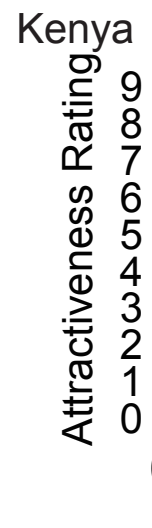

$y=-13.661 x+14.927$ $\mathrm{R}^{2}=0.2506$

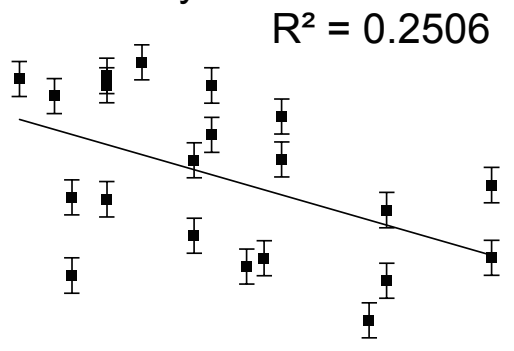

$\begin{array}{llllllll}0.55 & 0.6 & 0.65 & 0.7 & 0.75 & 0.8 & 0.85 & 0.9\end{array}$ Waist-to-Hip Ratio(WHR)
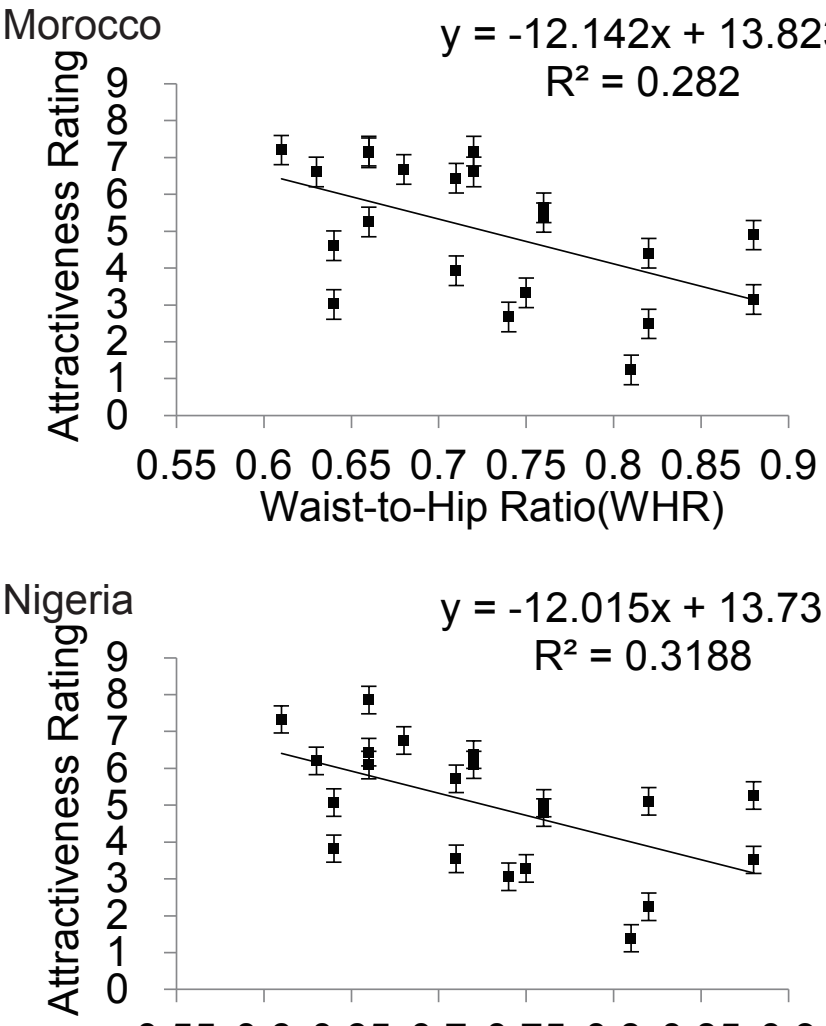

$$
\begin{gathered}
y=-12.015 x+13.731 \\
R^{2}=0.3188
\end{gathered}
$$

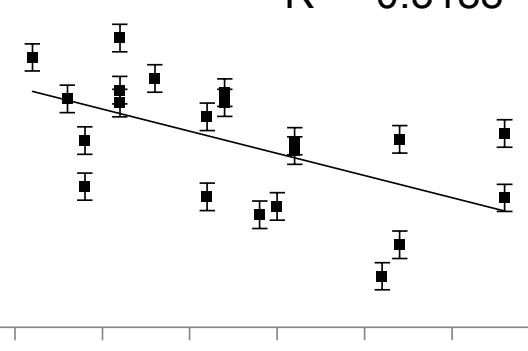

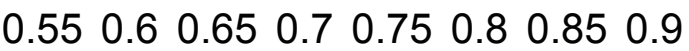
Waist-to-Hip Ratio(WHR)

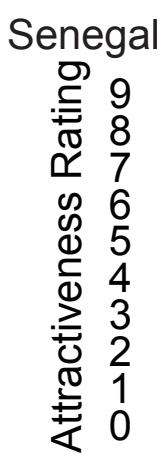

$$
\begin{gathered}
y=-9.0068 x+11.545 \\
R^{2}=0.2784
\end{gathered}
$$

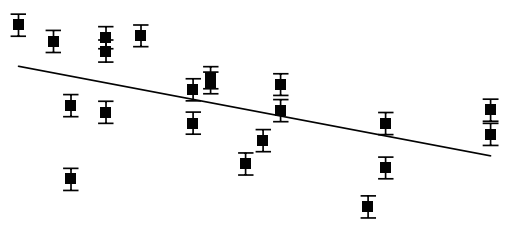

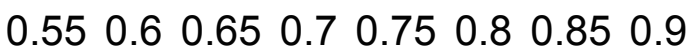
Waist-to-Hip Ratio(WHR) 
Figure 5 (on next page)

Relationships between estimated subject age and A) actual subject age, B) subject body fatness, C) subject BMI, D) subject WHR for 21 DXA soft tissue images averaged across 325 mixed sex raters in six different countries.

Relationships between estimated subject age and A) actual subject age, B) subject body fatness, C) subject BMI, D) subject WHR for 21 DXA soft tissue images averaged across 325 mixed sex raters in six different countries. 
A

B

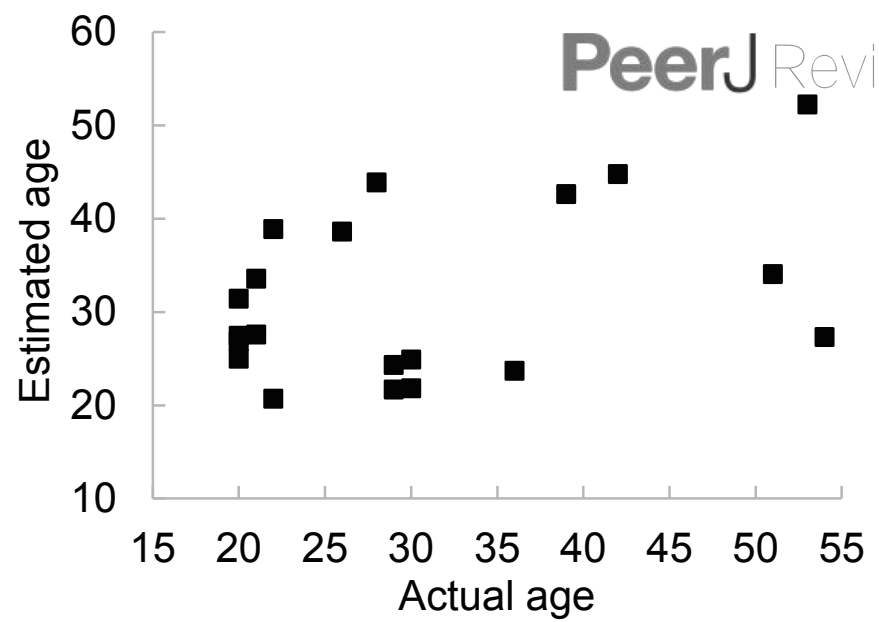

ing ${ }^{60}$ anuscript

$y=13.484 e^{0.0243 x}$ $\mathrm{R}^{2}=0.8119$
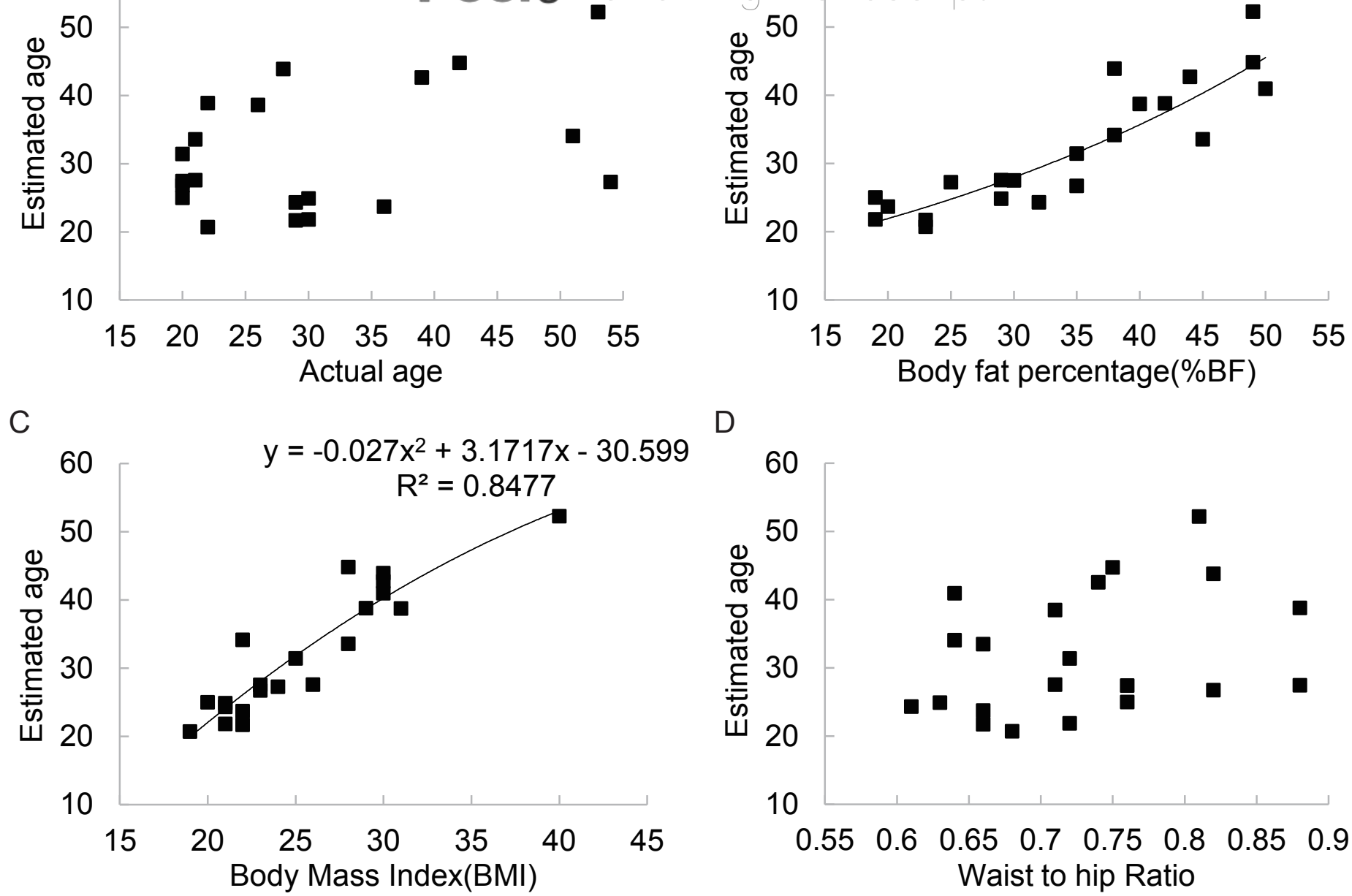

D

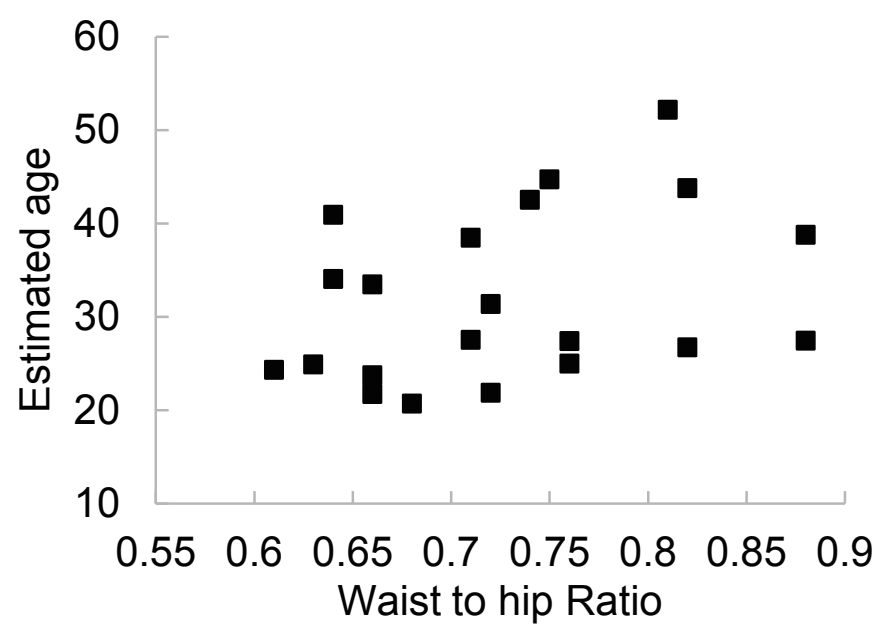

